\title{
Energetic Valorisation of Olive Biomass: Olive-Tree Pruning, Olive Stones and Pomaces
}

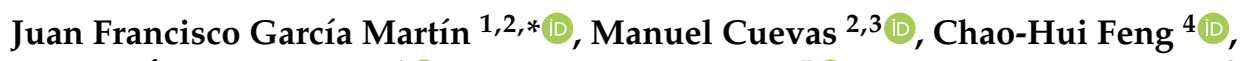 \\ Paloma Álvarez Mateos ${ }^{1}$ D , Miguel Torres García ${ }^{5}$ and Sebastián Sánchez ${ }^{2,3, *}$ \\ 1 Departamento de Ingeniería Química, Facultad de Química, Universidad de Sevilla, 41012 Sevilla, Spain; \\ palvarez@us.es \\ 2 Center for Advanced Studies in Olive Grove and Olive Oils, Science and Technology Park GEOLIT, \\ 23620 Mengibar, Spain; mcuevas@ujaen.es \\ 3 Department of Chemical, Environmental and Materials Engineering, University of Jaén, 23071 Jaén, Spain \\ 4 RIKEN Centre for Advanced Photonics, RIKEN, 519-1399 Aramaki-Aoba, Aoba-ku, Sendai 980-0845, Japan; \\ chaohui.feng@riken.jp \\ 5 Escuela Técnica Superior de Ingenieros Industriales, University of Seville-Thermal Power Group, \\ Camino de los descubrimientos s/n, 41092 Sevilla, Spain; migueltorres@us.es \\ * Correspondence: jfgarmar@us.es (J.F.G.M.); ssanchez@ujaen.es (S.S.)
}

Received: 20 March 2020; Accepted: 21 April 2020; Published: 26 April 2020

check for updates

\begin{abstract}
Olive oil industry is one of the most important industries in the world. Currently, the land devoted to olive-tree cultivation around the world is ca. $11 \times 10^{6}$ ha, which produces more than $20 \times 10^{6} \mathrm{t}$ olives per year. Most of these olives are destined to the production of olive oils. The main by-products of the olive oil industry are olive-pruning debris, olive stones and different pomaces. In cultures with traditional and intensive typologies, one single ha of olive grove annually generates more than $5 \mathrm{t}$ of these by-products. The disposal of these by-products in the field can led to environmental problems. Notwithstanding, these by-products (biomasses) have a huge potential as source of energy. The objective of this paper is to comprehensively review the latest advances focused on energy production from olive-pruning debris, olive stones and pomaces, including processes such as combustion, gasification and pyrolysis, and the production of biofuels such as bioethanol and biodiesel. Future research efforts required for biofuel production are also discussed. The future of the olive oil industry must move towards a greater interrelation between olive oil production, conservation of the environment and energy generation.
\end{abstract}

Keywords: bioethanol; combustion; gasification; olive; olive oils; olive-pruning debris; olive stones; olive pomaces; pyrolysis

\section{Introduction}

With the dramatic development of society, biofuels produced from biomass are regarded as a potential alternative source for energy and therefore solve the increasing energy crisis. Besides efficient food processing [1] and food safety inspection [2], an affordable, reliable, sustainable and modern energy is also an important sustainable development goal requested to be achieved.

The olive tree (Olea europaea L., subsp. europaea) belongs to the Oleaceae family. Over 11 million ha are devoted to olive tree cultivation around the world [3], resulting in more than 20 million $t$ of olives per year (Figure 1). The olive tree predominates in the agricultural production in the Mediterranean countries such as Spain, Italy, Greece, Turkey, Tunisia, Morocco, Syrian Arab Republic, Portugal, Egypt and Algeria (Figure 2), and it has been expanded in recent decades to other regions such as West Coast of the USA, Argentina, Australia, Chile, Peru, Uruguay and China [4]. Therefore, these countries are 
responsible for most of the worldwide production of olives (Figure 3). Olive tree not only supplies important olive oils providing us the healthiest vegetable fats, but also produces table olives, which are famous pickles for dishes starter.

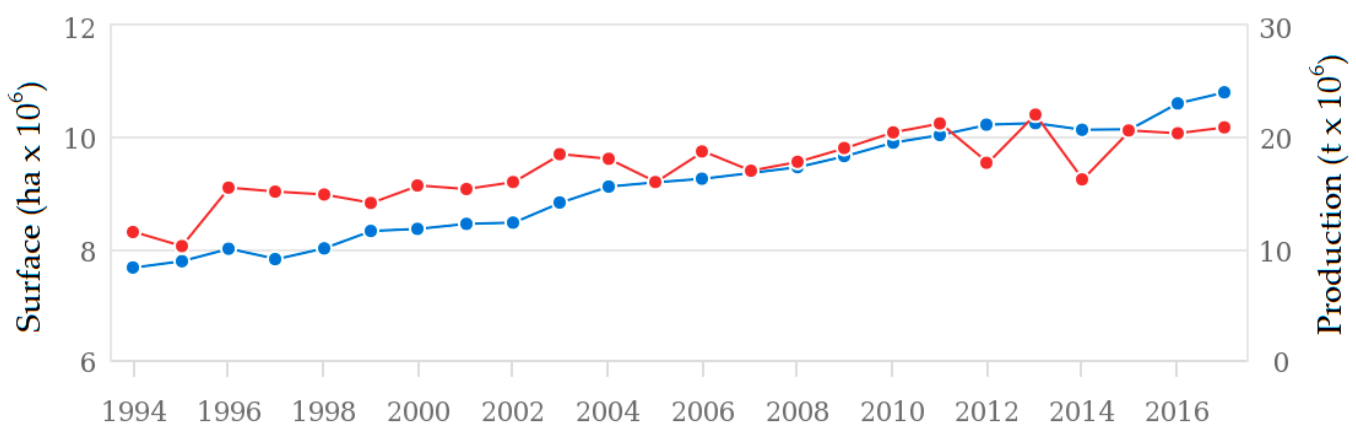

Figure 1. Total olive-tree cultivation surface (blue points) and worldwide olive production (red points) from 2001 to 2017. Reproduced with permission from FAOSTAT [5].

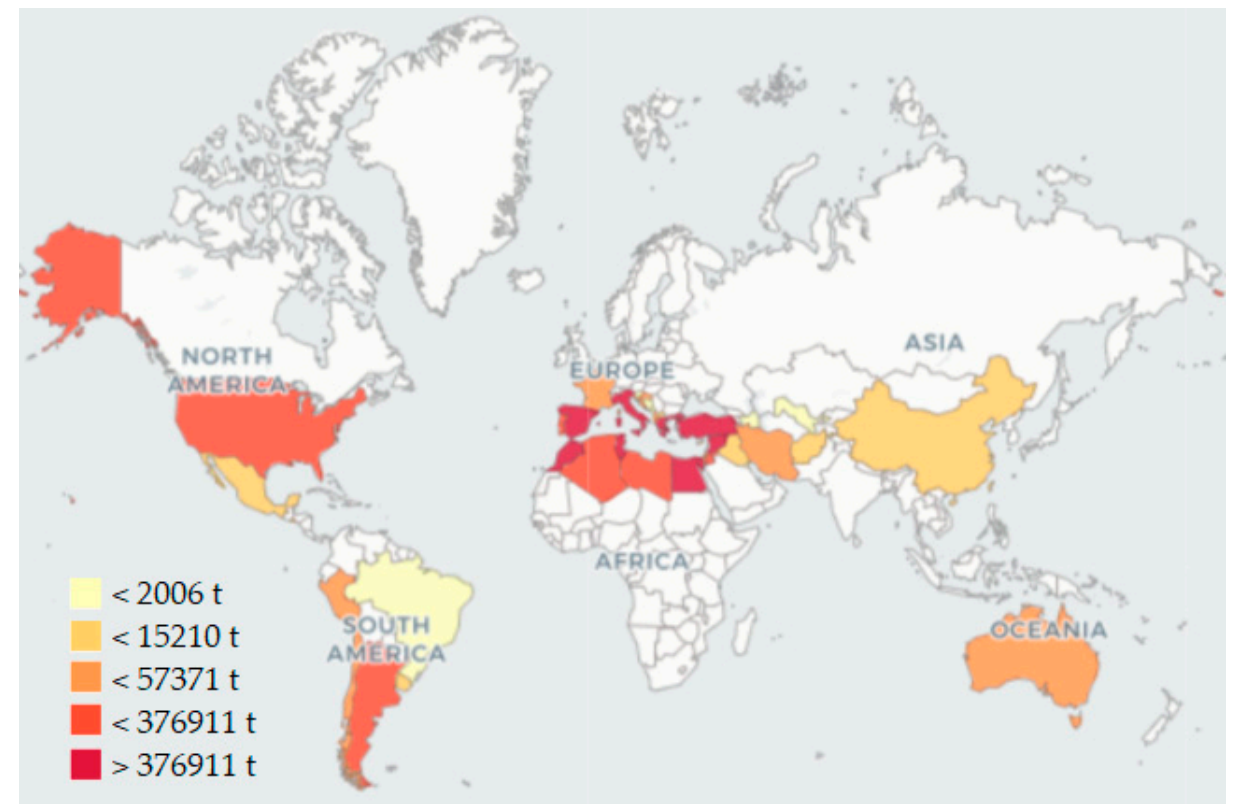

Figure 2. Average production of olives by country between 1994 and 2017. Reproduced with permission from FAOSTAT and OpenStreetMap Foundation [5].

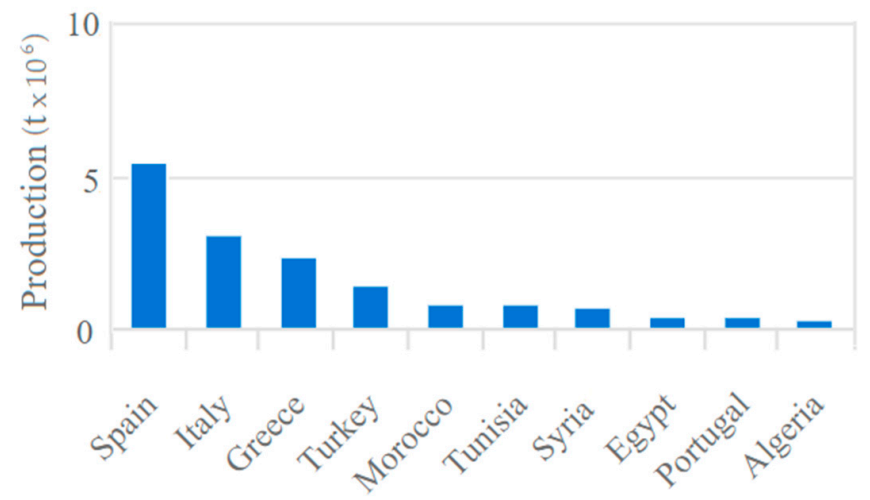

Figure 3. Average olive production (1994-2017) of the top 10 olive producers. Reproduced with permission from FAOSTAT [5]. 
The generation of by-products from the olive oil industry per ha of culture is illustrated in Figure 4. As it can be observed, the main by-products are olive-pruning debris (OP), olive stones (OS) and extracted pomace dry by-products.

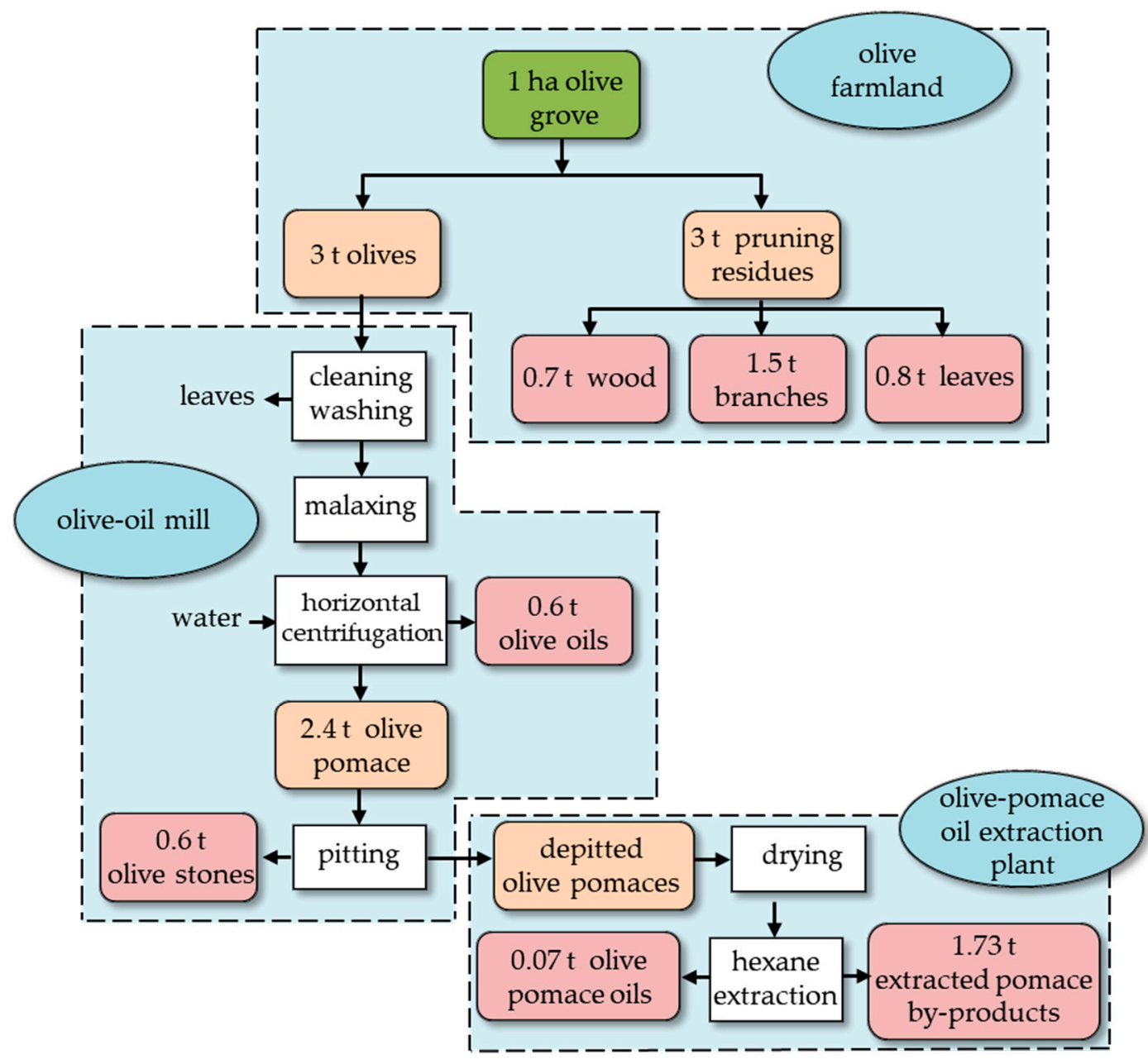

Figure 4. By-products obtained from olive orchards and olive mills.

Pruning is an important biennial operation carried out by farmers for removing old branches thus regenerating the tree. The olive-pruning debris consists of thin branches (usually $<5 \mathrm{~cm}$ diameter) and leaves. Leaves can be removed from the pruning debris by means of a densimeter machine for industrial applications. Farmers usually use the bigger branches and trunks in small home boilers. An average of 3 tons of olive-pruning debris is generated from a hectare of olive orchard [6], leading to producing more than $3.3 \times 10^{7}$ t biomass. Generally, the olive-pruning debris is either grinded and ploughed into soil or left on the land to be incinerated (Figure 5), which not only causes air pollution ( $\mathrm{CO}_{2}$ emissions) but also mineralizes the soil and increases the risks of pest propagation and fire accidents. The higher heating value (HHV) of the olive-pruning debris ranges between $16.7 \mathrm{MJ} / \mathrm{kg}$ and 19.8 MJ/kg [3,7-9], and its bulk density between $272 \mathrm{~kg} / \mathrm{m}^{3}$ [9] and $347.9 \mathrm{~kg} / \mathrm{m}^{3}$ [3]. The lower heating value (LHV) has been reported to be $16.55 \mathrm{MJ} / \mathrm{kg}$ [7]. If the olive pruning-debris were utilised to produce energy, it will not only maximise the reuse and exploitation of the value-added by-products, but also solve the environmental contamination and supply for the clean renewable energy. Its current price in Andalusia is 30-40€/t [3]. This low price makes OP an attractive material to produce pellets and other solid or liquid biofuels. 


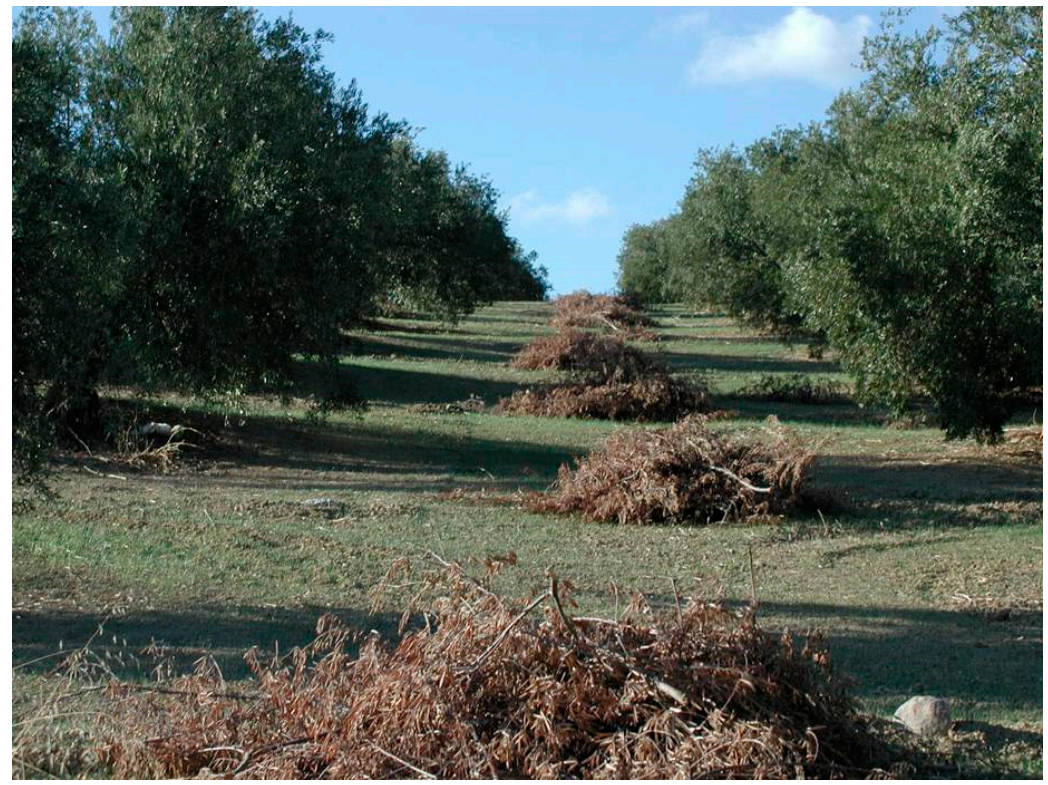

Figure 5. Olive-tree pruning piled up in the field.

Olive-tree pruning is a lignocellulose material and, therefore, is mainly composed of cellulose, hemicellulose and lignin (Table 1). Cellulose consists of thousands of chains, each chains made up of hundreds of D-glucose units linked up together by $\beta(1,4)$ glycosidic bonds with reducing and non-reducing ends. The presence of hydrogen bonds results in a crystalline structure [10]. The cellulose is wrapped in a sheath of hemicellulose and lignin, which protects cellulose from being broken down. Hemicellulose, which can account for between $15 \%$ and $35 \%$ of a lignocellulose material on a dry basis, is a heterogeneous polymer containing pentoses (D-xylose, L-arabinose), hexoses (D-mannose, D-glucose, D-galactose, and D-fructose), acetyl groups and uronic acids. This heteropolymer is easier to break down than cellulose. Lignin is mainly composed of guaiacyl, $p$-hydroxyphenyl and syringyl units polymerized by ether bonds or carbon-carbon linkages. Lignin provides chemical, mechanical and biological resistance to the lignocellulose material, and it is a potential source of aromatic compounds.

Table 1. Olive-pruning debris fiber composition.

\begin{tabular}{cccc}
\hline \multicolumn{3}{c}{ Composition (wt.\%) } & Reference \\
\cline { 1 - 3 } Cellulose & Hemicellulose & Lignin & \\
\hline 36.6 & 19.7 & 20.8 & {$[6]$} \\
30.3 & 17.9 & 24.1 & {$[4]$} \\
39.1 & 25.7 & 14.3 & {$[10]$} \\
36.4 & 21.5 & 17.1 & {$[11]$} \\
25.4 & 19.0 & 18.5 & {$[12]$} \\
25.0 & 18.3 & 18.8 & {$[13]$} \\
36.5 & 20.2 & 22.5 & {$[14]$} \\
36.5 & 20.8 & 21.3 & {$[15]$} \\
\hline
\end{tabular}

Regarding the elemental composition, scarce information is available in literature. However, the data provided by some authors confirms that sulphur is not detected in the olive-pruning debris (Table 2), which is characteristic of the olive-tree by-products. 
Table 2. Elemental analysis of the olive-pruning debris.

\begin{tabular}{cccccc}
\hline \multicolumn{5}{c}{ Element (\%) } & Reference \\
\cline { 1 - 5 } C & H & O & N & S & \\
\hline 44.6 & 6.7 & 47.9 & 0.8 & 0.0 & {$[6]$} \\
46.1 & 6.4 & 47.2 & 0.4 & 0.0 & {$[16]$} \\
\hline
\end{tabular}

Olive stones (Figure 6) are another biomass that is generated in olive oil mills. Olive table industry annually generates around 30,000 $\mathrm{t}$ olive stones [17]. Besides, olive stones are also generated in olive oil and olive pomace oil extractor industries after separating the olive stones from the olive pulp to obtain olive oil or olive pomace oil, respectively. In both cases, the size of the crashed endocarps never exceeds $7 \mathrm{~mm}$ in length. Most of the olive stones recovered in olive mills have sizes larger than $1 \mathrm{~mm}$, the percentage of thinner solids increasing when increasing the weight of the pulp and inorganic matter in the olive. Saleh et al. (2014) reported that $97.3 \%$ (wt.\%) of the olive stones collected in an olive mill had sizes greater than $1.2 \mathrm{~mm}$ [18]. Mata-Sánchez et al. (2015) found that $96.3 \%$ of their olive stones samples had diameters higher than $1.4 \mathrm{~mm}$ [19]. Furthermore, Fernández-Bolaños et al. (1999) and Barreca and Fichera (2013) reported maximum olive stones sizes of $6.2 \mathrm{~mm}$ and $1.6 \mathrm{~mm}$, respectively $[20,21]$. This small particle size of olive stones is an advantage over other biomasses with larger sizes (e.g., olive prunings), avoiding the need to resort costly milling stages for subsequent use. Notwithstanding, its current price ( $80-100 € / t$ in Andalusia, Spain) is much higher than that of olive-tree pruning [3].

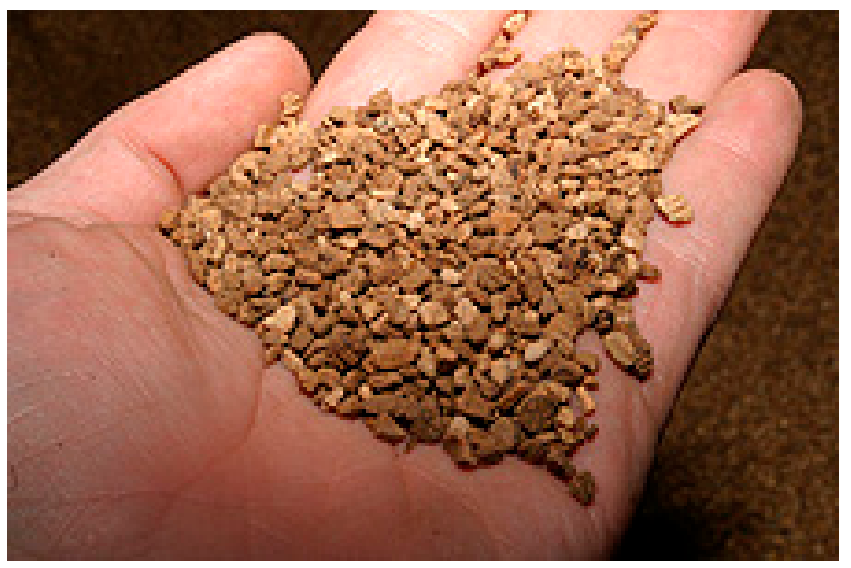

Figure 6. Endocarps from olive fruit.

Olive stones account for roughly $20 \%$ of the olive weight. Thus, it was reported that $100 \mathrm{~kg}$ fresh olives contain $22 \mathrm{~kg}$ olive stones (4 $\mathrm{kg}$ seeds plus $18 \mathrm{~kg}$ endocarps) [22]. As a lignocellulose material, its main components are cellulose, hemicellulose and lignin (Table 3). As it can be observed, the percentage of hemicellulose in OS is higher than in OP. The different olive varieties, geographical location, the presence of traces of pulp and pericarp, and the analytical techniques used by the different authors could account for the different results shown of results in Table 3.

Table 3. Fiber composition of olive stones.

\begin{tabular}{cccc}
\hline \multicolumn{3}{c}{ Composition (wt.\%) } & \multirow{2}{*}{ Reference } \\
\cline { 1 - 3 } Cellulose & Hemicellulose & Lignin & \\
\hline 29.9 & 28.1 & 27.7 & {$[23]$} \\
33.5 & 24.5 & 23.1 & {$[22]$} \\
27.1 & 32.2 & 40.4 & {$[24]$} \\
36.4 & 26.8 & 26.0 & {$[25]$} \\
\hline
\end{tabular}


Due to its high lignin content, it was reported to be suitable for thermal utilization. Olive stones were reported to have a great potential as solid biofuel for combustion in comparison with other lignocellulose materials. An average lower heating value of $19,167 \mathrm{kcal} / \mathrm{kg}$ was obtained from 30 different olive stones obtained from different regions of Andalusia (Spain) [17]. Concerning the higher heating value, different authors have pointed out that the HHV of olive stones ranged between $18.8 \mathrm{MJ} / \mathrm{kg}$ and $20.9 \mathrm{MJ} / \mathrm{kg}$ [3,17], these HHV measured by different methods. As a result, $99 \%$ of olive stones produced are currently used as solid biofuel to thermal power generation.

Olive stones possess a relatively low ignition point (approximately $215^{\circ} \mathrm{C}$ ) while the maximum combustion rate is $0.341 \mathrm{dm}^{3} / \mathrm{min}$ and is achieved at $284^{\circ} \mathrm{C}$. As little mineral matter is contained in olive stones and their ash melting temperature was over $1400{ }^{\circ} \mathrm{C}$, it thus reduces costs of burner cleaning. The bulk density of olive stones is $721.6 \mathrm{~kg} / \mathrm{m}^{3}$ [3], double than that of olive-pruning debris, which accounts for the aforementioned potential of olive stones for combustion. On the other hand, as a type of lignocellulose material, it has been proposed as a source of fermentable sugars, antioxidants and other applications [26]. If added-value products can be obtained from olive stones from thermochemical and biochemical points of view, it will greatly solve the problem of environmental contamination.

With regard to elemental composition, sulphur is barely detected in olive stones, as it is characteristic of olive tree by-products (Table 4). Among the different trace elements present that can be found, chlorine and copper can be highlighted, with concentrations ranging from $90 \mathrm{mg} / \mathrm{kg}$ to $435 \mathrm{mg} / \mathrm{kg}$ and from $0.6 \mathrm{mg} / \mathrm{kg}$ to $2.3 \mathrm{mg} / \mathrm{kg}$, respectively [19,27]. Ash percentages are usually lower than $2 \%$ (wt.) (Table 4). The main inorganic compounds found in olive stones ash are $\mathrm{Al}_{2} \mathrm{O}_{3}, \mathrm{CaO}$, $\mathrm{Fe}_{2} \mathrm{O}_{3}, \mathrm{~K}_{2} \mathrm{O}, \mathrm{MgO}$, and $\mathrm{SiO}_{2}$ [28-30].

Table 4. Elemental analysis and ash content of olive stones.

\begin{tabular}{ccccccc}
\hline \multicolumn{6}{c}{ Composition (wt.\%). } & \\
\cline { 1 - 5 } C & H & O & N & S & Ash & \\
\hline 51.2 & 6.0 & 41.9 & 0.15 & 0.02 & 0.78 & {$[19]$} \\
50.1 & 5.9 & 42.0 & 0.6 & 0.02 & 1.33 & {$[31]$} \\
46.6 & 6.3 & 45.2 & 1.8 & 0.10 & 1.40 & {$[32]$} \\
48.6 & 5.7 & 44.1 & 1.6 & 0.05 & 1.90 & {$[33]$} \\
\hline
\end{tabular}

The extraction process of olive oils has evolved over the years from discontinuous to continuous methods. In the first method, olive oil was obtained by applying hydraulic pressure (press method). Nevertheless, the olive oil industry has been modernized with the introduction of continuous methods by centrifugation. In the first instance, process with decanter of three outlets (olive oil, pomace and wastewater) were used. From the 1990s and with the aim of reducing the environmental impact of the wastewater generated by this process, the number of outlets in the horizontal centrifuge was reduced from three to two outlets, one for olive oil and the other for olive pomace and vegetable water (plus the added water during the process). Therefore, the type of pomaces and their physicochemical characteristics depend on the kind of process (Table 5).

Table 5. Physicochemical characteristics of the pomaces based on the process used.

\begin{tabular}{ccccc}
\hline Process & $\begin{array}{c}\text { Moisture and } \\
\text { Volatile Matter } \\
\text { \% }\end{array}$ & $\begin{array}{c}\text { Fat Matter } \\
\text { \% (In Wet Basis) }\end{array}$ & $\begin{array}{c}\text { Fat Matter ** } \\
\text { \% (In Dry Basis) }\end{array}$ & $\begin{array}{c}\text { Production * } \\
\text { kg/t Olives }\end{array}$ \\
\hline Pressure & $22-35$ & $5.0-8.0$ & $7.0-11.0$ & $250-350$ \\
Three outlets & $45-55$ & $3.0-4.5$ & $6.0-8.0$ & $450-520$ \\
Two outlets & $65-75$ & $2.0-3.5$ & $6.0-7.5$ & $800-850$ \\
\hline
\end{tabular}

* Data from [34]; ** Own data. 
In Spain, the country with the highest olive production, the most widely used olive oil extraction process is the continuous centrifugation system using two-outlet decanters (Figure 7). In Italy, the second olive producing country, pressure systems, centrifugation with a three-outlet decanter and, to a lesser extent, the system with a two-outlet decanter are used. In Greece and the other countries of the Mediterranean basin the three systems are used, although the most widespread is the centrifugation process with two-outlet decanter. The same happens in the rest of the olive oil producing countries (Portugal, Argentina, Uruguay, Chile, Peru, Australia, USA and China).

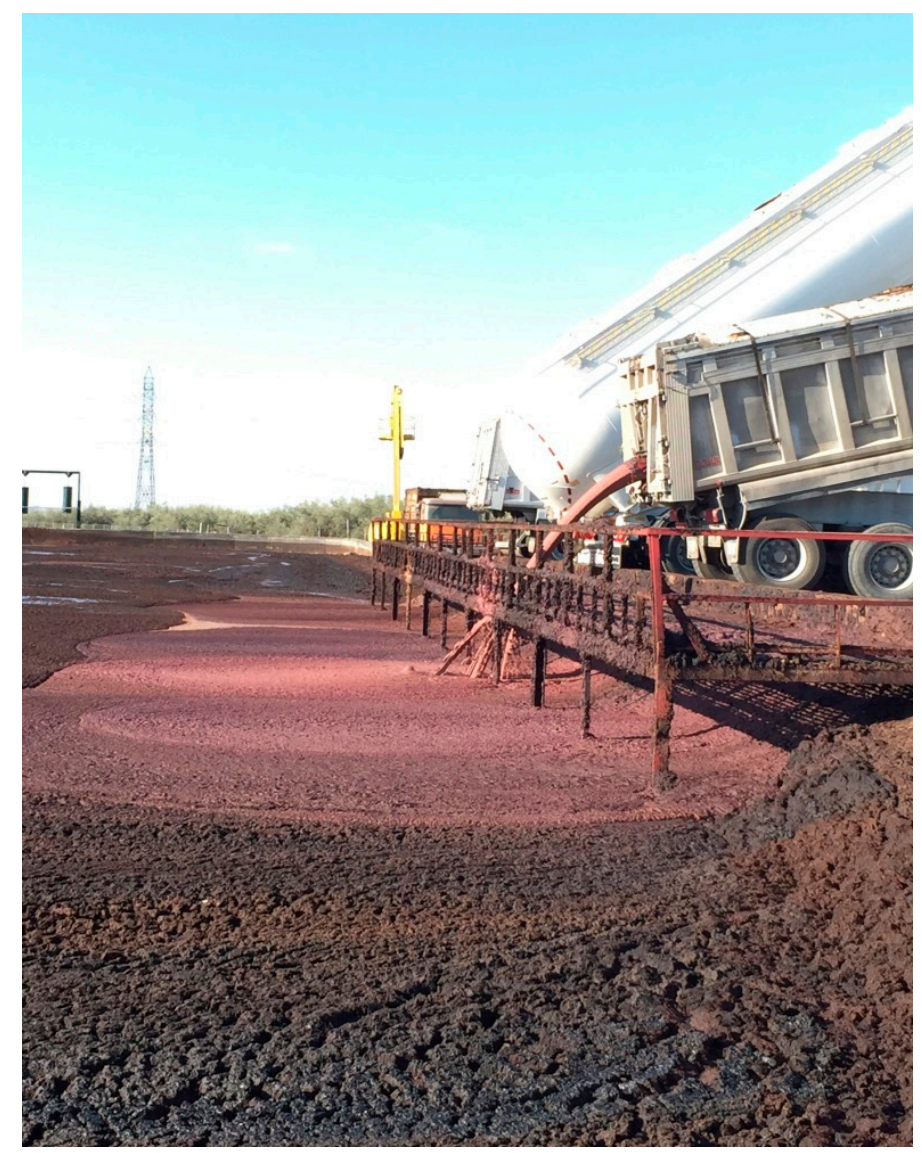

Figure 7. Olive pomace from oil mills that use the centrifugation process with a two-outlet decanter. These pomace rafts are located in the extraction plants of pomace oils.

In general, the pomaces produced are transported to the pomace extraction plants to separate the residual oil that they still contain. In these facilities, the extraction of residual oil is carried out using a solid-liquid extraction process, being technical hexane (mixture of alkanes) the most widely used solvent. From this process, crude pomace oil and a by-product that is extracted pomace are obtained. Crude pomace oils are sent to oil refining plants to obtain olive pomace oil. On the other hand, the extracted pomace (by-product from extraction process) constitutes a very interesting solid biofuel and with $\mathrm{HHV}$ in the range of 13.8 to $15.8 \mathrm{MJ} / \mathrm{kg}$.

All these studies highlighted an unyielding interest in exploiting biomass obtained from olive tree. Therefore, the objective of this paper is to comprehensively review the latest advances focused on energy production from olive-pruning debris, olive stones and olive pomaces. The different routes to produce energy from these by-products are summarized in Figure 8 and discussed in the following sections. Future research efforts required to biofuel production are also discussed. 


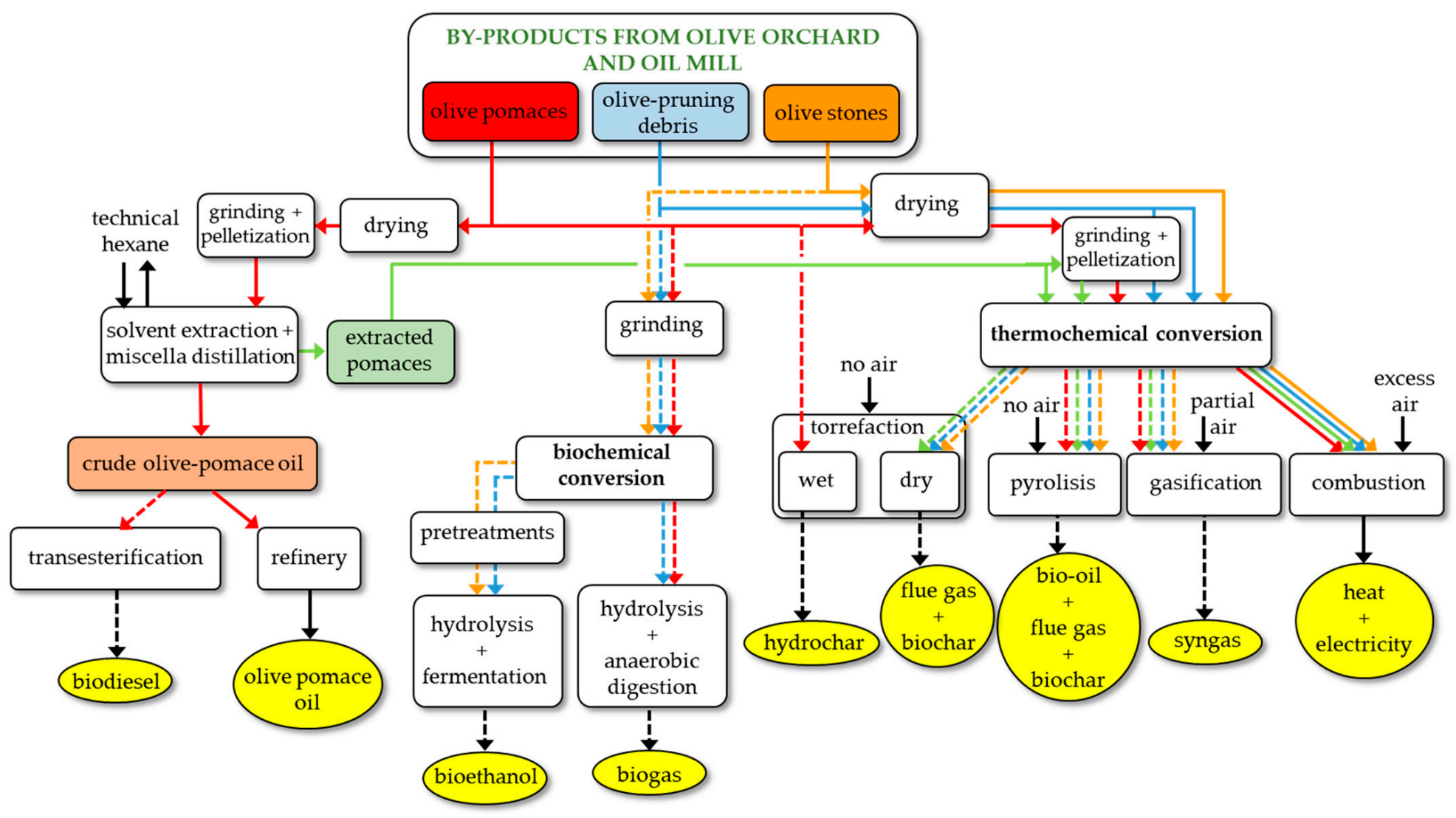

Figure 8. Valorisation routes of olive mills by-products towards energy. Solid lines stand for actual industry processes while dashed lines represent potential applications at research stage. 


\section{Olive-Pruning Debris}

As the rest of lignocellulose wastes, the olive-pruning debris is a major potential source for renewable energy and high-value chemical products. Currently, the most direct application of the pruning debris is for combustion. Thicker branches are sometimes separated and used as firewood for home or small industries. However, this direct combustion is an inefficient process for energy conversion that is responsible of large $\mathrm{CO}_{2}$ emissions. Assuming complete combustion under ideal conditions, extremely unlikely to occur, and an average carbon content in OP of $45.35 \%$ (Table 2), $1.7 \mathrm{~kg}$ of $\mathrm{CO}_{2}$ would be emitted to the atmosphere per $\mathrm{kg}$ of burnt pruning. The combustion reactions and kinetics of OP can be found elsewhere [8]. As no sulphur is detected in the pruning and its nitrogen content is small, which are major advantages from the environmental point, other energy production processes have been researched in the last decades, as below indicated.

\subsection{Bioethanol Production}

As a lignocellulose waste, and thus a sugar-rich substrate, OP pruning is suitable for bioethanol production. Furthermore, its high cellulose content and low lignin content (Table 1), compared to other lignocellulose waste, makes OP an excellent substrate for bioethanol production. Currently, the bioethanol production includes 4 stages: (1) pre-treatment, (2) hydrolysis of polysaccharides and oligosaccharides into monomer sugars, (3) fermentation of sugars to ethanol, and (4) ethanol concentration to absolute alcohol. These stages and their applications to OP are comprehensively detailed in the following subsections.

\subsubsection{Pre-Treatment}

Since lignocellulose biomass is a mixture of carbohydrate polymers from plant cell walls, the pre-treatment process is thus required to reduce the feedstock size, break down the hemicellulose to sugars and open the structure of the cellulose. Two parallel phases, i.e., a hemicellulose-rich liquid and a cellulose-rich solid, will be formed. Following this, the cellulose is hydrolyzed by enzymes into D-glucose that could be fermented into ethanol. Likewise, the D-xylose, mainly from the hemicellulose, could be fermented to ethanol or xylitol. Lignin can be extracted from the cellulose-rich solid by using an alkaline solution. As a result, an alkaline residue containing lignin is formed, which can be extracted by oxidizing agents, such a $\mathrm{H}_{2} \mathrm{O}_{2}$ [35], thus reducing the volume of the hydrolysis reactor, increasing sugar concentration, and reducing the energy consumption the subsequent cellulose hydrolysis. In spite of these advantages, this step is not mandatory to improve the enzymatic digestibility of cellulose. Among the pre-treatments applied to $\mathrm{OP}$, the most widely used are:

- Ultrasound pre-treatment

Ultrasound technology, which produces cavitation and acoustic streaming, has also been regarded as a promising pre-treatment for the degradation of lignin. The particles nearby can be crumbled because the powerful hydro-mechanical shear forces in the bulk liquid is generated. Ultrasound irradiation disrupted lignocellulose structure and breakdown the crystalline nature of cellulose structure, apart from provoking cellulose depolymerisation and solubilisation, lysis of cell walls and membranes as well as improvement of the solubilisation of organic matter [36]. It was demonstrated that a hydrodynamic shear force in aqueous phase was generated from ultrasound, which increased the disintegration of coarse particles and so promoted the surface area for enzyme activity [37]. As the cavitation can generate high temperatures and high pressures (often referred as "hot spots"), the reaction times in heterogeneous solid-liquid systems can be reduced and the chemical degradation could be accelerated via the production of oxidative species. Combined with other biomass pre-treatments such as ozone or alkaline pre-treatment, a decrease of hemicellulose and lignin content was observed when sugarcane bagasse was pre-treated by ultrasound [38].

Notwithstanding, there is a lack of papers concerning the application of ultrasound to OP as a pre-treatment in the bioethanol production scheme. Nevertheless, some works can be found in 
literature. Thus, The application of ultrasound to OP to extract antioxidant compounds has been assessed [39]. Different ethanol/water ratios ( $20 \%, 50 \%$ and $80 \%$ of ethanol concentration), amplitude percentages (30\%, 50\% and 70\%) and process times ( $5 \mathrm{~min}, 10 \mathrm{~min}$ and $15 \mathrm{~min}$ ) were assessed. From the results on total phenolic compounds, total flavonoid content and antioxidant activities, these authors concluded that ultrasound pre-treatment could be a first step of the process within a biorefinery context and OP a potential source of natural antioxidants [39]. In the available literature it can be also found the effects of ultrasonic treatments on organosolv black liquor from olive tree pruning residues [40]. Up to $20 \%$ monosaccharides were degraded when $15 \mathrm{~min}$ of ultrasound treatment was applied. The monomeric sugars were increased from $3 \%$ to $16 \%$ as result of the lignin-carbohydrate complex rupture that was caused by ultrasonic irradiation [40].

\section{- Ozonation}

Ozone, the strongest chemical oxidant after fluorine, can be utilised as pre-treatment for removing the lignin from the lignocellulose biomass and finally improving the enzymatic degradation. Compared with other conventional pre-treatment methods, no harm residue such as acids or mineral bases are produced after ozonation [41]. Unlike ultrasound pre-treatment that is carried out at extremely high temperatures and pressures, ozone reactions can occur even at room temperature and pressure. Besides, ozone could be generated in situ in the bioethanol plant, thus avoiding transportation and storage issues.

Although ozonation has been demonstrated to be an effective pre-treatment, it is regarded as uneconomical due to the assumed need for lignin mineralization [42]. In order to overcome this issue, ozonation has been applied to tannic acid to simulate the effects of ozonation process on biomass pre-treatment for bioethanol production [42]. A high concentration of tannic acid solution $\left(60 \mathrm{~g} / \mathrm{dm}^{3}\right)$, as a lignin model, was treated by ozonation. Most of tannic acid was disappeared after $3.5 \mathrm{~h}$ treatment. As a negative result, tannic acid negatively affected cellulases activity. Despite the aforementioned doubt of widespread application to biomass as a pre-treatment, it was stated that a short-time ozonation, as an alternative, could reduce the pre-treatment energy costs from about $\sim \$ 104.28$ to $\sim \$ 2.22$ per ton of biomass and thus cut down the labor costs and operation times [42]. In spite of these advantages, to the best of our knowledge there are not available works on the use of ozonation as OP pre-treatment for bioethanol production.

- Steam explosion

Steam explosion, where the biomass is subjected to pressurised steam injected to a high temperature $\left(180-240^{\circ} \mathrm{C}\right.$ ) for a short time (from $10 \mathrm{~s}$ to several minutes) and ends with a sudden decompress of the system, is a widely used pre-treatment of biomass. The cellulose and lignin degraded by the high temperature whilst the tissue structure damaged during the rapid pressure release. In this way, the biomass is easier to be hydrolysed and fermented. A high D-xylose yield can be achieved especially when an acid catalyst is applied. The role of sulphuric acid (as catalyst) is to hydrolyse the hemicellulose into monomers without degrading them furfural and 5-hydroxy-methyl furfural (5-HMF). As a result, the addition of an acid catalyst can reduce the processing temperature to $150-200{ }^{\circ} \mathrm{C}$, thus improving the subsequent enzymatic hydrolysis. Steam explosion has been applied to OP and these facts have been verified. In this way, it was reported the solubilisation of hemicellulose from olive tree pruning was improved by using steam explosion at temperatures between $190^{\circ} \mathrm{C}$ and $240{ }^{\circ} \mathrm{C}$ [13]. Other acids have been used to improve the steam explosion of OP, such as phosphoric acid [43]. Furthermore, the steam explosion of olive tree pruning has been investigated at pilot scale to maximize the glucose yield in the subsequent enzymatic hydrolysis [44].

- Autohydrolysis or liquid hot water (LHW) pre-treatment

This technique is quite similar to the steam explosion and leads to similar results. LHW refers to the process of solubilisation of hemicellulose in pressurized water at temperatures ranging between 
$165^{\circ} \mathrm{C}$ and $225^{\circ} \mathrm{C}$ [45]. The hemicellulosic acetyl groups are rapidly released, thus hydrolyzing the rest of hemicellulose (autohydrolysis). To determine the effect of this pre-treatment, the severity parameter, $R_{0}$, is calculated as follows:

$$
R_{0}=\int_{0}^{t} \exp ^{\frac{T(t)-T_{R}}{w}} d t
$$

where $T(t)$ is the temperature $\left({ }^{\circ} \mathrm{C}\right.$ )-time ( $\mathrm{min}$ ) function, calculated graphically, and $T_{\mathrm{R}}$ a reference temperature $\left(100^{\circ} \mathrm{C}\right)$ below which the autohydrolysis can be considered of scarce significance [46]. The value of 14.75 is the generally used for the parameter $w$ in the autohydrolysis of olive pruning debris [47].

LHW pre-treatment has been applied to OP in the temperature range $150-210{ }^{\circ} \mathrm{C}$ for short reaction times $(0-5 \mathrm{~min})$ at the selected temperature (average $\left.R_{0}=3.54 \pm 0.06\right)$, resulting in a complete solubilisation of hemicellulose [4,47]. Similarly to steam explosion, LHW leads to a hemicellulosic oligomers solution which requires a further acid hydrolysis to release the monomeric sugars, if they are intended to be fermented [48]. To avoid the application of two pre-treatments, it has been assayed the addition of dilute acid into the pressurized water reactor, thus performing simultaneously both autohydrolysis and dilute-acid hydrolysis. Although it is performed in pressurized water reactors, this combined technique is generally referred as dilute-acid hydrolysis in spite of using high pressures, achieving high sugars yields and complete hemicellulose solubilisation when applied to OP [4].

\section{- Extrusion}

Continuous extrusion process, which involves a single or twin-screw extruder combining thermal, mechanical and chemical action, is regarded as a cost-effective pre-treatment method for enzymatic saccharification. What is more, the addition of enzymes during the extrusion process (bioextrusion) as new biomass pre-treatment technique for second generation bioethanol production has been proposed, resulting in a better sugar production [49]. With regards to its application to OP, extrusion in a twin-screw extruder was applied to $\mathrm{OP}$ to remove the extracts and the amorphous cellulose at $70{ }^{\circ} \mathrm{C}$ and sulphuric acid concentrations lower than $0.5 \mathrm{~mol} / \mathrm{dm}^{3}$ [10]. The yield of sugars was low. However, combined with a subsequent dilute-acid hydrolysis with $1 \mathrm{~mol} / \mathrm{dm}^{3} \mathrm{H}_{2} \mathrm{SO}_{4}$ of the resulting solid in a stirred-tank reactor, led to a sugar-rich hydrolysate [14]. Extrusion operation still needs to be optimised for the extrusion to be regarded as a single hydrolysis stage for bioethanol production.

\section{- Dilute-acid hydrolysis}

Dilute-acid pre-treatment, as one of the most important pre-treatments, has been widely applied to OP within the biorefinery concept. The aim of dilute acid is to solubilise the hemicellulose fraction without degrading cellulose as far as possible. With regards to the application of dilute-acid pre-treatment to OP, several authors have reported that hemicellulose depolymerised into a mixture of sugar oligomers and monomers under the acidic, thermal process while scarce alteration took place in lignin and cellulose structures $[4,11,50,51]$. In addition, cellulose porosity increased with the removal of hemicellulose and so enhanced enzymatic digestibility of the cellulose. The effects of temperature and acid concentration of dilute-acid pre-treatment on the subsequent simultaneous saccharification and fermentation of olive-pruning debris using response-surface methodology (RSM) have been studied. The pre-treatment led to a complete solubilisation of the hemicellulose. As a result, the cellulose percentage in the resulting solid was roughly 1.5 times as much as that for raw material [4]. According to the RSM, the highest overall ethanol yields would be obtained when the pre-treatment for olive-pruning debris were performed with $0.059 \mathrm{kmol} / \mathrm{m}^{3}$ and $0.030 \mathrm{kmol} / \mathrm{m}^{3} \mathrm{H}_{2} \mathrm{SO}_{4}$ at $185^{\circ} \mathrm{C}$. Under these conditions, $15.3 \mathrm{~kg}$ and $14.5 \mathrm{~kg}$ ethanol would be generated from $100 \mathrm{~kg}$ olive-pruning debris, respectively [4]. Likewise, the effects of the reaction time (0-300 $\mathrm{min})$, temperature $\left(70-90^{\circ} \mathrm{C}\right)$ and sulphuric acid concentration $\left(0-0.05 \mathrm{kmol} / \mathrm{m}^{3}\right)$ on the formation of D-glucose and D-xylose were evaluated by RSM [50]. Results showed that there were interactive effects between the three parameters on sugars production. The highest concentrations of D-glucose and D-xylose were achieved when 
the highest temperature, acid concentration and residence time applied. The optimal conditions for generating D-xylose were $90{ }^{\circ} \mathrm{C}, 0.05 \mathrm{kmol} / \mathrm{m}^{3} \mathrm{H}_{2} \mathrm{SO}_{4}$ and $300 \mathrm{~min}$ reaction time. Under these conditions, it was predicted that approximately $40 \%$ of the maximum attainable D-glucose and $60 \%$ of the potential D-xylose would be obtained [50]. The olive-pruning debris has been also hydrolyzed by $0.050-0.100 \mathrm{kmol} / \mathrm{m}^{3}$ oxalic acid at $130-170{ }^{\circ} \mathrm{C}$ for 30 min using $1: 10$ dry raw material to organic acid ratio. However, the hydrolysate was not able to be fermented by the yeast Pichia stipitis CBS 6054 [14]. Similarly, the fermentation with Pachysolen tannophilus of the hydrolysates resulting from the hydrolysis with concentrated phosphoric acid of OP at $90^{\circ} \mathrm{C}$ for $240 \mathrm{~min}$ led to very low bioethanol yields [52].

Dilute-acid pre-treatment has been assayed in combination with other pre-treatments, such as fungal pre-treatment [51] and autohydrolysis [15,48], to enhance the enzymatic hydrolysis of OP. For instance, the combination of fungal pre-treatment with a dilute-acid pre-treatment was studied [51]. It was found that the order of the pre-treatment combination has a relevant effect on the D-glucose yield of the subsequent enzymatic hydrolysis. The application of the best pre-treatments combination plus enzymatic hydrolysis to OP achieved $51 \%$ of the theoretical sugar yield. The afore mentioned best sequential pre-treatments were fungal pre-treatment with Irpex lacteus for 28 days followed by diluted-acid pre-treatment with $2 \%(w / v) \mathrm{H}_{2} \mathrm{SO}_{4}$ at $130^{\circ} \mathrm{C}$ for $90 \mathrm{~min}$, which enhanced $34 \%$ the enzymatic hydrolysis yield compared with that of the application of solely the dilute-acid pre-treatment [51]. On the other hand, the application of an dilute-acid hydrolysis $\left(90^{\circ} \mathrm{C}, 0.05 \mathrm{kmol} / \mathrm{m}^{3} \mathrm{H}_{2} \mathrm{SO}_{4}\right)$ to the solid obtained after the autohydrolysis $\left(200^{\circ} \mathrm{C}, 0 \mathrm{~min}\right)$ of olive-pruning debris, neither increased the cellulose conversion nor led to lignin degradation [48]. By contrast, the application of the same dilute-acid pre-treatment to the resulting liquid from autohydrolysis rocketed the D-glucose and D-xylose extraction from OP. As a result, this sequential pre-treatments led to a phenolic compound-free pre-hydrolysate containing $114 \mathrm{~g}$ D-glucose and $78 \mathrm{~g}$ D-xylose per pre-treated $\mathrm{kg}$ of olive-tree pruning [48]. This fact has been verified by other authors, who stated that in all their experiments the percentage of lignin recovered was close to $100 \%$ [15]. These authors concluded that the dilute-acid hydrolysis of OP at $90{ }^{\circ} \mathrm{C}$ for $180 \mathrm{~min}$ leads to an almost complete hydrolysis of the hemicellulose when using a concentration of hydrochloric acid $(\mathrm{HCl})$ exceeding $3.77 \%$.

- $\quad$ Alkaline peroxide pre-treatment

Alkaline peroxide, during which effective radicals perform the delignification without degrading sugars, is also widely used as pre-treatment for biomass saccharification [53]. Since it is difficult for chemicals and enzymes to access to cellulose due to its complex glycosidic and hydrogen bonds network, an alternative strategy is to remove lignin to easier access to cellulose carbohydrates in the subsequent enzymatic hydrolysis.

Under alkaline conditions, hydrogen peroxide can attack the phenolic compounds, which is quite different from that under the normal conditions where hydrogen peroxide can only react with the aliphatic part of lignin without degrading the phenolic compounds [54]. Lignin was reported to be effectively removed from the olive-tree pruning biomass when treated with formic acid and alkaline hydrogen peroxide, allowing the production of ethanol up to $46 \mathrm{~g} / \mathrm{dm}^{3}$ in the subsequent enzymatic hydrolysis and fermentation [12].

\subsubsection{Hydrolysis}

Acid hydrolysis was the main technique for lignocellulose hydrolysis in the 20th century for ethanol production because mineral acids can penetrate lignin without pre-treatment and the rate of acid hydrolysis is faster than enzymatic hydrolysis. Notwithstanding, sugars also degrades rapidly under acidic conditions to compounds such as furfural, a product of dehydration of pentoses, and 5-hydroxymethylfurfural, a product of the dehydration of hexoses (Figure 9). These compounds, along with the acetic acid released during initial decomposition of the hemicellulose, inhibit the later fermentation, leading to reduced ethanol yields [55]. Furthermore, the use of high temperatures and 
acid concentrations is dangerous and leads to severe corrosion of equipment and the need to recover the acid used, after hydrolysis, to make it economically feasible [56]. As a result, this technique has been replaced by the enzymatic hydrolysis when the goal is to obtain D-glucose from cellulose, and it is usually used as a pre-treatment, under mild conditions, of the enzymatic process as aforementioned.

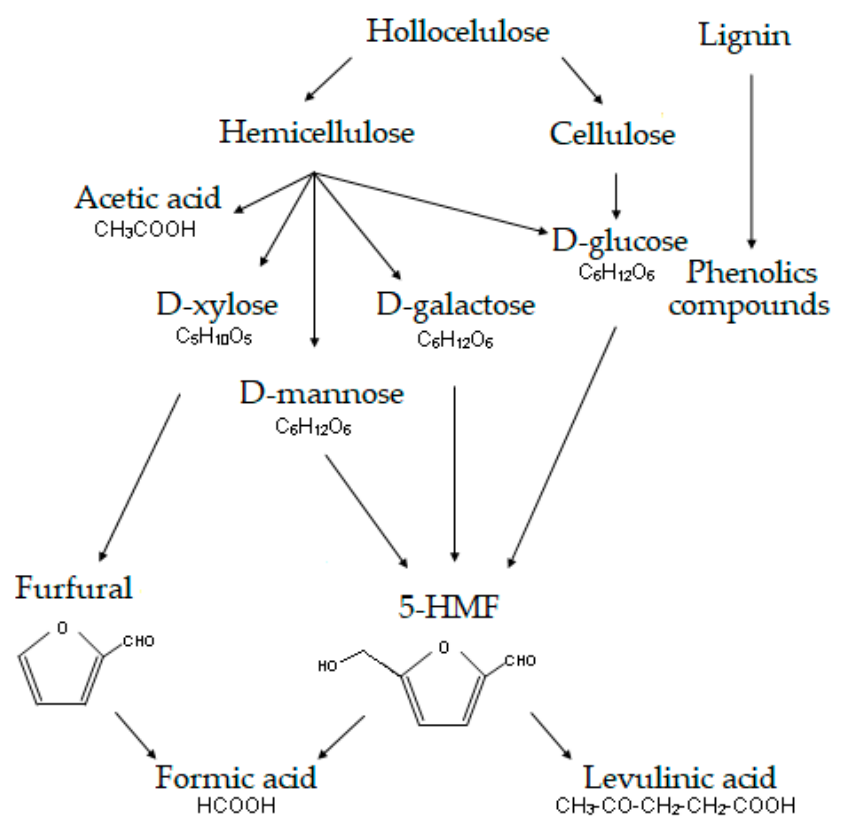

Figure 9. Products and by-products obtaining during the acid hydrolysis of lignocellulose biomass.

Enzymatic hydrolysis began to be researched from the seventies of last century with the first commercial preparations of biocatalysts. Its main advantages are that the enzymatic reactions are carried out under mild conditions $\left(40-50{ }^{\circ} \mathrm{C}\right.$ and $\mathrm{pH}$ around 5.0) and its selectivity. The cellulases used for breaking down cellulose are originated from fungi, especially from Trichoderma reesei or Trichoderrma viride. A single enzyme is unable to hydrolyse the whole lignocellulose biomass and most cellulases are complexes of three type of enzymes that hydrolyse cellulose together. First, an endoglucanase breaks one of the chains within the cellulose crystalline structure. Then, an exoglucanase attaches to one of the loose ends, pulls the cellulose chain out of the crystal structure, and works its way down the chain, breaking off units of cellobiose (two linked D-glucose units). Finally, a $\beta$-glucosidase splits the cellobiose into two D-glucose molecules [56]. Cellulases and $\beta$-glucosidases are inhibited by cellobiose and D-glucose, respectively.

Aiming to a full valorisation of the sugars contained in the olive-pruning debris, it is mandatory to hydrolyse hemicellulose. To this end, xylanases are required to break down the linear $\beta-1,4$-xylan polysaccharide to D-xylose. Generally, both xylanases and cellulases are added to the resulting mixture from the pre-treatment, i.e., the pre-hydrolysate (rich in oligomers from hemicellulose) and the cellulose-rich solid are simultaneously hydrolysed to cut costs. Industrial cellulases and xylanases are well-known commercial products, tailor-made according to the desired commercial application [56].

The so-called simultaneous saccharification and fermentation (SSF) greatly improves D-glucose yield, reducing the concentration of required enzyme. During SSF, enzymes hydrolyse cellulose chains and yeasts ferment D-glucose to ethanol at the same time, so that the inhibition by degradation products will be lessened when sugars fermented immediately after generation. The ethanol production from OP by SSF of the pre-treated solid has been already investigated using a commercial cellulolytic complex (Celluclast $1.5 \mathrm{~L}$ ) and the yeast Saccharomyces cerevisiae [4,13]. Using as pre-treatment steam explosion [13] or autohydrolysis [4] acid-catalyzed, the ethanol yields were 7.2 and $9.9 \mathrm{~kg} / \mathrm{kg}$ OP, respectively. 


\subsubsection{Fermentation}

The conventional yeast Saccharomyces cerevisiae is the most common yeast for alcoholic fermentation because it can easily convert D-glucose into ethanol, reaching fermentation yields (expressed as $\mathrm{kg}$ ethanol per $\mathrm{kg}$ total sugars) close to the maximum theoretical ethanol yield $(0.51 \mathrm{~kg} / \mathrm{kg})$ with volumetric productivities of up to $5 \mathrm{~kg} / \mathrm{m}^{3} \mathrm{~h}$ and final ethanol concentrations of roughly $10 \%(v / v)$ [57]. Moreover, it can be used for continuous industrial processes. Notwithstanding, this yeast is unable to ferment D-xylose and the rest of pentoses from hemicellulose. Therefore, other yeasts able to ferment both hexoses and pentoses into ethanol have been assayed, such as Pichia stipitis, Candida shehatae, Candida tropicalis and Pachysolen tannophilus. Some of them ferment D-xylose to xylitol instead of to ethanol (C. tropicalis, P. tannophilus), depending on the oxygen conditions [47,58,59].

Olive-pruning-debris hydrolysates have been fermented with several of these yeasts. In order to reduce cost, a scheme consisting in dilute-acid hydrolysis plus fermentation, thus eliminating the costly enzymatic hydrolysis stage, has been assayed by several authors $[15,16,52,60]$. Hydrolysates obtained from the dilute-acid hydrolysis of $\mathrm{OP}$ at $90^{\circ} \mathrm{C}$ with hydrochloric, sulphuric and trifluoroacetic acids in concentrations between $0.1 \mathrm{~N}$ and $1.0 \mathrm{~N}$ were fermented with $P$. tannophilus. The highest ethanol yield ( $0.37 \mathrm{~kg}$ ethanol $/ \mathrm{kg}$ total sugars) was achieved in the fermentation of hydrolysates obtained with 0.1 $\mathrm{N} \mathrm{C}_{2} \mathrm{HF}_{3} \mathrm{O}_{2}$ [60] while the highest ethanol concentration $\left(6.34 \mathrm{~g} / \mathrm{dm}^{3}\right)$ was found in the hydrolysate from hydrolysis with $1.0 \mathrm{~N} \mathrm{HCl}$ [60]. Lower yields were found by these authors using phosphoric acid hydrolysates [60]. Anyway, with regard to the overall process, the production of ethanol from initial dry olive-pruning debris was almost negligible (Table 6). This was probably because dilute-acid hydrolysis solely solubilized sugars from hemicellulose. Therefore, cellulose remained in the solid and its D-glucose was not fermented. Similarly, the fermentation with $P$. tannophilus of the hydrolysates resulting from the hydrolysis with concentrated phosphoric acid of OP at $90{ }^{\circ} \mathrm{C}$ for $240 \mathrm{~min}$ led to very low bioethanol yields instead of the high fermentation yield ( $0.38 \mathrm{~kg}$ ethanol $/ \mathrm{kg}$ total sugars) [52]. Furthermore, the hydrolysates obtained from dilute-acid hydrolysis using $0.050-0.100 \mathrm{kmol} / \mathrm{m}^{3}$ oxalic acid at $130-170{ }^{\circ} \mathrm{C}$ for 30 min could not be fermented by the yeast P. stipitis CBS 6054 [14], probably to production of yeast inhibitors from sugar degradation. The best results of the application of this scheme to $\mathrm{OP}$ has been achieved using $1 \mathrm{~N} \mathrm{H}_{2} \mathrm{SO} 4$ at $90{ }^{\circ} \mathrm{C}$ for $240 \mathrm{~min}$ [16]. These authors obtained $70 \mathrm{~g}$ ethanol plus $34 \mathrm{~g}$ xylitol (a high-added value by-product) per $\mathrm{kg} \mathrm{OP}$, reaching fermentation yields higher that the aforementioned (Table 6).

Another interesting scheme applied to OP is autohydrolysis plus fermentation without enzymatic hydrolysis [47]. As it can be seen in Table 6, this scheme resulted in the production of $7.2 \mathrm{~g}$ of ethanol from $100 \mathrm{~g}$ of olive pruning debris along with an instantaneous ethanol yield of $0.44 \mathrm{~kg} / \mathrm{kg}$ total sugars. In spite of the fact that these two schemes, which do not involve enzymatic hydrolysis, do not take advantage of the most of D-glucose of cellulose, they are less costly and provide a solid residue composed of cellulose and lignin that is an excellent raw material for pellet production, thus leading to a circular economy of the olive-tree pruning.

With regard to the last scheme, consisting of pre-treatment, enzymatic hydrolysis and subsequent fermentation, it is worth noting that the ethanol yield achieved using steam explosion plus SSF with S. cerevisiae of the pre-treated cellulose [13] was similar to that obtained by autohydrolysis and fermentation of the prehydrolysate [47], which had the advantage of the non-use of enzymes (Table 6). The use of an acid catalyst in the pre-treatment increased the ethanol yield in the SSF of the pre-treated cellulose up to $9.9 \mathrm{~kg} / \mathrm{kg}$ [4]. To improve these ethanol yields, it is mandatory to ferment the pre-hydrolysate, rich in hemicellulosic sugars. The yeasts used by several authors to ferment pre-hydrolysates from OP were Scheffersomyces stipites [43] and Escherichia coli [12]. The ethanol production from both fermentation of hemicellulosic sugars solubilized in the pre-treatment and SSF of pre-treated cellulose was roughly $16 \mathrm{~kg} / \mathrm{kg}$ OP. [4,12,43]. Notwithstanding, the use of enzymes and 2 fermentation stages make this scheme infeasible from an economic point of view. 
Table 6. Ethanol yields obtained from olive-pruning debris (OP) using different hydrolysis plus fermentation schemes

\begin{tabular}{|c|c|c|c|c|c|c|}
\hline Pre-Treatment & Commercial Enzyme Preparation & SSF Yeast & Fermentation Yeast & Fermentation Yield (kg/kg) & Overall Yield (kg/kg OP) & Reference \\
\hline $0.5 \mathrm{~N} \mathrm{H}_{3} \mathrm{PO}_{4}, 90^{\circ} \mathrm{C}, 240 \mathrm{~min}$ & - & - & P. tannophilus & 0.38 & NP & [52] \\
\hline $1 \mathrm{NC}_{2} \mathrm{HF}_{3} \mathrm{O}_{2}, 90^{\circ} \mathrm{C}, 240 \mathrm{~min}$ & & & P. tannophilus & 0.37 & NP & [60] \\
\hline $75 \mathrm{mM} \mathrm{C}_{2} \mathrm{H}_{2} \mathrm{O}_{4}, 150^{\circ} \mathrm{C}, 240 \mathrm{~min}$ & - & - & P. stipitis & 0.00 & 0.00 & [14] \\
\hline $1 \mathrm{~N} \mathrm{H}_{2} \mathrm{SO}_{4}, 90^{\circ} \mathrm{C}, 300 \mathrm{~min}$ & - & - & C. tropicalis & 0.42 & 0.070 & [16] \\
\hline${ }^{*} \log R_{0}=3.54$ & - & - & C. tropicalis & 0.44 & 0.072 & [47] \\
\hline$* 230^{\circ} \mathrm{C}, 1 \%$ (wt.) $\mathrm{H}_{2} \mathrm{SO}_{4}$ impregnation & Novozymes Celluclast 1.5 L and Novozymes 188 & S. cerevisiae & - & - & 0.072 & [13] \\
\hline${ }^{*} 0.08 \mathrm{~N} \mathrm{H} 2 \mathrm{SO} 4,107^{\circ} \mathrm{C}, 5 \mathrm{~min}$ & Novozymes Celluclast $1.5 \mathrm{~L}$ and Novozymes 188 & S. cerevisiae & - & - & 0.099 & [4] \\
\hline $\begin{array}{l}2.4 \% \text { (wt.) } \mathrm{H}_{2} \mathrm{SO}_{4} 130^{\circ} \mathrm{C}, 84 \mathrm{~min}+7 \% \mathrm{H}_{2} \mathrm{O}_{2} \\
(w / v), 80^{\circ} \mathrm{C}, 90 \mathrm{~min}\end{array}$ & Novozymes Cellic CTec3 and Novozymes 50010 & S. cerevisiae & E. coli & 0.43 & 0.15 & [12] \\
\hline$* * 1 \%$ (wt.) $\mathrm{H}_{3} \mathrm{PO}_{4}, 195^{\circ} \mathrm{C}, 10 \mathrm{~min}$ & Novozymes 50013 and Novozymes 50010 & S. cerevisiae & S. stipitis & 0.35 & 0.16 & [43] \\
\hline
\end{tabular}

${ }^{*}$ Liquid hot water; ${ }^{* *}$ Steam explosion; $\mathrm{NP}=$ not provided. 


\subsection{Methane Generation}

Scarce information about methane production from OP can be found in literature. The finest OP particles have been reported as the most suitable for methane production due to their high concentration of nitrogenous matter and low $\mathrm{C} / \mathrm{N}$ ratios, which make these $\mathrm{OP}$ suitable for anaerobic digestion [61]. After the application of a fractionation process to obtain the finest OP particles and the subsequent batch anaerobic digestion at $38^{\circ} \mathrm{C}$, the highest methane yield achieved by these authors was $176.5 \mathrm{Nm}^{3}$ per $t$ volatile solids, which accounted for $93.5 \%$ gains over the untreated OP. The authors described their process as highly energy efficient, since energy consumption was low compared with the energy required by the residues of fuel upgrading, intended for anaerobic digestion [61]. Nevertheless, there is other olive mill wastes with higher potential for anaerobic digestion and therefore methane production, such as olive pomace and, mainly, olive mil wastewater. Thus, about 10-12 million cubic meters of olive mill wastewater are generated every year from the olive oil extraction in 2-and 3-outlet decanters in a relatively short period of time, so that researchers have put a lot of effort to cope with this issue, mainly through biogas production. This could account for the scarce available information on methane production from OP [62].

\subsection{Pellets Production}

The production of pellets from the olive-pruning debris is a low-cost alternative that would allow the conversion of this waste into an energy resource that could be used in the surrounding areas where the OP was collected or be packaged for external sales. In both cases, it would suppose a benefit for farmers. Notwithstanding, it has to be taken into account that some authors have pointed out that OP meets the specification for industrial pellets given in the European Standard EN ISO 17225-2, but not for residential pellets based on this standard because of its high ash and nitrogen content [7,61]. Another hindrance for pellets production from OP is its low bulk density $\left(347.9 \mathrm{~kg} / \mathrm{m}^{3}\right.$ [3]). The use of denser biofuels reduces the costs associated with handling, storage and transportation [7]. One suggested alternative is to mix $\mathrm{OP}$ with other raw materials in order to reduce the percentages of these chemical components in the final biomass and increase bulk density [7]. The effects of main process parameters (pressure and temperature) and OP properties (moisture content and particle size) on pellet density and durability have been previously investigated [63]. High process temperatures, low moisture contents (less than 15\% [64]) and reduced particle sizes were reported as the conditions to obtain high-quality pellets from OP, while the compression force had scarce effect on pellet quality [63]. In this sense, $9 \%$ moisture content along with short compression lengths $(20-24 \mathrm{~mm}$ ) and temperatures higher than $40^{\circ} \mathrm{C}$ were reported as the most suitable pelleting conditions for the residual biomass from olive trees (leaves, prunings and wood), although these parameters varied among the raw materials analyzed [7]. The pelleting process slightly increase the calorific power of this biomass. Thus, the HHV and LHV of pellets from OP have been reported to be 19.47 and $16.17 \mathrm{MJ} / \mathrm{kg}$, respectively [64].

\subsection{Torrefaction}

Torrefaction is a pre-treatment applied to enhance biomass properties for its further use in combustion or pyrolysis processes. Concerning to OP, torrefaction was carried out under an inert atmosphere at low temperature $\left(200-300^{\circ} \mathrm{C}\right.$ ) and a low heating rate (residence time between $10 \mathrm{~min}$ and $60 \mathrm{~min}$ ) to convert this biomass into a charcoal-like carbonaceous material with enhanced energetic properties [65]. For example, torrefaction at $300^{\circ} \mathrm{C}$ for $60 \mathrm{~min}$ led to an increase on the ratio of fixed carbon to volatiles (from 0.23 to 0.39 ), improving the fuel quality of OP. Under these conditions, the OP surface structure was broken, hemicellulose was partially or totally decomposed, and under the severest torrefaction conditions, a modification on the thermal stability of cellulose was observed. These authors also proposed a pyrolysis kinetic model of OP through thermogravimetric measurements under $\mathrm{N}_{2}$ atmosphere during the torrefaction of OP under different conditions [66]. Three stages in which the activation energy kept approximately constant were observed. These stages were related to the 
thermal degradation of the 3 main constituents of any lignocellulose biomass: cellulose, hemicellulose and lignin.

\subsection{Pyrolysis}

Pyrolysis is a thermal process carried out under partial or complete absence of oxygen and is based on capturing the off-gases from thermal decomposition of the organic material. Three main products are obtained from biomass pyrolysis: Syngas (non-condensable gases), bio-oil (hydrocarbon molecules) and a solid residue rich in carbon. Syngas and bio-oils are regarded as ordinary energy carriers. Besides, bio-oils from pyrolysis are of major interest, as they can replace diesel in internal combustion engines [67]. Among these different products obtained from biomass pyrolysis, the solid, carbon-rich material can be highlighted. This solid can be biochar or charcoal. Biochar is mainly used for soil applications for both agriculture and environment, while the charcoal is used as a fuel for heat, absorbent material, or reducing agent in metallurgical processes [64]. Slow pyrolysis is applied for retaining up to $50 \%$ of the carbon feedstock in the resulting biochar so that it can be used as soil fertilizer while high-temperature pyrolysis $\left(>550^{\circ} \mathrm{C}\right)$ led to biochar with high aromatic content from lignin decomposition and, therefore, recalcitrant to decomposition [64]. The biochar obtained by these latter authors from the pyrolysis or OP pellets showed HHV and LHV of 31.71 and $30.48 \mathrm{MJ} / \mathrm{kg}$, respectively [64], far higher than those reported for OP [3,7-9] and pellets from OP [64]. This biochar can be certified as Biochar Premium according to the regulations of the European Biochar Certificate, based on the analysis of nutrients and trace elements, polycyclic aromatic hydrocarbons composition, elemental analysis, $\mathrm{pH}$, electrical conductivity and density performed by the authors [64].

In an earlier work, leaves, branch barks, twigs (small branch of $1 \mathrm{~cm}$ ) and olive wood (sawdust particle size $0.8-1 \mathrm{~mm}$, cubes of $1,2,3$, or $4 \mathrm{~cm}$ edge) were subjected to pyrolysis at 400,500 and $600{ }^{\circ} \mathrm{C}$ $\left(10^{\circ} \mathrm{C} / \mathrm{min}\right.$ heating rate, $20 \mathrm{~min}$ residence time at the final temperature, $200 \mathrm{~cm}^{3} / \mathrm{min} \mathrm{N}_{2}$ stream) [68]. Based on its high content of volatile matter and ash and the low process yield, the charcoal obtained from the pyrolysis of olive leaves was regarded as low-quality charcoal. These authors pointed out that since olive leaves are used to feed cattle, this is a more appropriate alternative to pyrolysis [68]. By contrast, in spite of the fact the charcoals obtained from the pyrolysis of branch bark, twig and wood (sawdust or cubes) also had a high ash content, their volatile matter and fixed carbon contents made them suitable for the production of B category briquettes in accordance with the French and Belgian regulations in force at the date of publication of that paper [68], both regulations were dating from 1984. With regards to the effect of temperature pyrolysis on the resulting charcoals, the fixed carbon content increased and that of the volatile matter decreased as the temperature in which the process was performed rose from $400{ }^{\circ} \mathrm{C}$ to $600^{\circ} \mathrm{C}$. Finally, the Brunauer-Emmett-Teller (BET) surface area of the charcoals obtained from leaves and branch barks were very low ( 5 and $16 \mathrm{~m}^{2} / \mathrm{g}$, respectively), while those of twigs and different olive woods ranged between $19 \mathrm{~m}^{2} / \mathrm{g}$ and $198 \mathrm{~m}^{2} / \mathrm{g}$ [68]. These surface area values are lower than those obtained for charcoals of other biomasses. For instance, BET surface area of coconut shell biochar was reported to be $244.2 \mathrm{~m}^{2} / \mathrm{g}$ [69] and that of biochars obtained from the pyrolysis of roots from Jatropha curcas L. plants used for the phytoremediation of contaminated soils with different heavy metal concentrations soils was $447 \mathrm{~m}^{2} / \mathrm{g}$ [70]. Notwithstanding, scanning electron microscopy (SEM) analysis indicated that the surface of biochar from OP was higher than that of OP surface, and that it had a very porous structure, indicating that it could be regarded as an ideal support for metal impregnation [9].

The pyrolysis of OP has been modelled from thermogravimetric experimental data of each obtained fraction of the lignocellulose material (cellulose, hemicellulose and lignin) [8]. It was reported that the pyrolysis of OP could be divided into three stages: those of hemicellulose, cellulose and lignin, respectively. Lignin was the component most difficult to decompose and it occurred slightly over a wide temperature range, with a very low mass loss [8]. Therefore, the pyrolysis of OP is strongly influenced by its lignin content. 
The pyrolysis under inert atmosphere $\left(\mathrm{N}_{2}\right)$ and under oxidizing atmosphere $\left(20 \% \mathrm{O}_{2}\right)$ of OP, OP soaked with $\mathrm{Ni}$ solutions and $\mathrm{OP}$ soaked with $\mathrm{Pb}$ solutions has been investigated with a heating rate of $10^{\circ} \mathrm{C} / \mathrm{min}$ [9]. For the 3 biomasses, the greatest mass loss under was found in the ranges $150-400{ }^{\circ} \mathrm{C}$ and $150-480^{\circ} \mathrm{C}$ under inert atmosphere and oxidizing atmosphere, respectively. In contrast with the OP impregnated with nickel, the impregnation with lead did not show very significant effects. The maximum volatilization rate was observed for the nickel-impregnated OP. As a result, there was a higher emission of volatile compounds and a higher mass loss in the gasification of OP soaked with nickel [9].

A pyrolysis-based circular system from the OP obtained from 10 ha olive grove, i.e., $25 \mathrm{t}$ twigs (32 wt.\% moisture) and $10 \mathrm{t} 4$-cm diameter wooden branches (40 wt.\% moisture), has been proposed [67]. This scheme is based on the OP pyrolysis at $600{ }^{\circ} \mathrm{C}$ with an approximate heating rate of $200{ }^{\circ} \mathrm{C} / \mathrm{s}$ under He atmosphere. The pyrolysis of this OP led to $8.5 \mathrm{t}$ of bio-oil with (average LHV of $31 \mathrm{MJ} / \mathrm{kg}$ ), $9.9 \mathrm{t}$ of gas and $7.4 \mathrm{t}$ of bio-char (average LHV of $29 \mathrm{MJ} / \mathrm{kg}$ ). The gross energy obtained from the combustion of these $8.5 \mathrm{t}$ bio-oil as a fuel (assuming 30\% combustion efficiency) and the heat recovery from the dryer was $23.43 \mathrm{MWh}$ [67]. These authors stated that the $7.4 \mathrm{t}$ of biochar obtained from 10 ha olive grove could be used as soil amendment and carbon sequestration tool, which could make pyrolysis a suitable process for olive groves with poor soil and in conditions where soil management needs are preeminent [67].

Finally, low-temperature microwave-assisted pyrolysis of olive pruning residue using various absorbers has been assayed [71]. The bio-oils obtained contained interesting bio-chemical compounds (mainly acetic acid, aromatics and furans) while biochars showed calorific values close to that of commercial pellets (up to $25 \mathrm{MJ} \mathrm{kg}^{-1}$ ). These authors concluded that the microwave-assisted pyrolysis of OP can be a sound method for obtaining useful chemicals and fuels, thus representing a potential possibility for reducing all of the environmental risks involved in its disposal [71].

\subsection{Gasification}

Gasification is a process based on the partial oxidation of the biomass with a controlled amount of oxygen or steam carried out at high temperatures $\left(>700{ }^{\circ} \mathrm{C}\right)$, i.e., gasification does not involve combustion, resulting in the production of syngas $\left(\mathrm{H}_{2}\right.$ and $\mathrm{CO}$, mainly) and condensable organic compounds as gasification byproducts. Gasification is a mature technology since it has been extensively applied for decades in the gas industry. Notwithstanding, some authors has pointed out that gasification is having its own rejuvenation due to its application to biomass, which is regarded as a new substrate for this process [67].

The gasification of OP has been studied in a laboratory fluidized bed [72]. The influence of temperature $\left(800-900{ }^{\circ} \mathrm{C}\right.$ ), equivalence ratio (0.12-0.35), fuel particle size (from $0.5-4 \mathrm{~mm}$ to $2.5-4 \mathrm{~mm}$ ), biomass throughput (485-725 kg/h m²) and $\mathrm{O}_{2}\left(21\right.$ and $40 \% \mathrm{O}_{2}$ in air) was investigated. These authors analyzed the results with the assistance of a previously developed fluidized bed gasification model. The application of this model to the laboratory-scale results allowed predicting the gas composition of industrial-scale fluidized bed gasifiers [72].

The gasification kinetics of olive tree pruning pellets in fluidized bed at temperatures between $760{ }^{\circ} \mathrm{C}$ and $900{ }^{\circ} \mathrm{C}$ has been described [73]. These authors prepared cylindrical pellets from OP using a pelletizing machine, which were reduced to $1-2.8 \mathrm{~mm}$ (average $1.9 \mathrm{~mm}$ ) and $2.8-4 \mathrm{~mm}$ (average $3.4 \mathrm{~mm}$ ) particle size by grinding. Experiments were carried out using gas mixtures containing $\mathrm{H}_{2} \mathrm{O}$, $\mathrm{CO}_{2}, \mathrm{H}_{2}, \mathrm{CO}$ and $\mathrm{N}_{2}$ in various proportions at a superficial gas velocity of approximately $0.50 \mathrm{~m} / \mathrm{s}$. CO and $\mathrm{H}_{2}$ inhibited the gasification process in a significant way. The authors obtained 2 kinetic equations, one for the gasification rate with $\mathrm{H}_{2} \mathrm{O}$, which took into account the inhibition effect of $\mathrm{H}_{2}$, and another for gasification with $\mathrm{CO}_{2}$, which included the inhibition effect of $\mathrm{CO}$. The reaction rate of the former one (gasification with $\mathrm{H}_{2} \mathrm{O}$ ) was from 3 to 4 times faster than that of the latter one (gasification with $\mathrm{CO}_{2}$ ) [73]. These kinetic models accounted for the effect of temperature, gas composition and the extent of carbon conversion. 
The effects of nickel and lead as catalyst on the gasification of olive pruning under oxidizing and inert atmosphere have been assessed [9]. To do that, samples were soaked with nickel and lead solutions. Under nitrogen inert atmosphere, the effect of both metals catalyst was negligible and they were concentrated in the ash, thus increasing the concentration of metals in ash. The same occurs with lead under oxidizing atmosphere $\left(20 \% \mathrm{O}_{2}\right)$. By contrast, an increase in thermal decomposition was observed due to the presence of nickel under oxidizing atmosphere, probably because of the formation of $\mathrm{NiO}$, which catalyzed decomposition reactions [9].

A gasification-based circular system has been proposed based on a bubbling fluidized bed gasifier working at about $800{ }^{\circ} \mathrm{C}$ and using a constant equivalence ratio (0.3) during the operation (50 t of air in the gasifier) [67]. As substrate, these authors used the annual OP obtained from 10 ha olive grove in Foggia province (Southern Italy, Apulia region): $25 \mathrm{t}$ twigs (32 wt.\% moisture) and $10 \mathrm{t}$ larger wooden branches of at least $4 \mathrm{~cm}$ of diameter (40 wt.\% moisture). From these, $62 \mathrm{t}$ of syngas with an energy content of $88 \mathrm{MWh}$ were obtained. Considering an electricity conversion efficiency for the syngas obtained from gasification of $37.5 \%$ for electricity production in a micro turbine (Brayton Cycle) and taking also into account the recovery of heat from the dryer, the total gross amount of energy reached 34.4 MWh [67]. These authors concluded this electricity generated is far more enough to supply the energy requirements of the olive-olive mill that produces the olive oil from the olives collected in that 10-ha olive grove.

The gasification of OP through a downdraft fixed bed reactor showed that the composition of syngas was strongly influenced by the air flow rate [74]. The $\mathrm{H}_{2}$ and $\mathrm{CO}$ contents were roughly $16 \%$ $(v / v)$ and over $13 \%(v / v)$, respectively, while the $\mathrm{CH}_{4}$ content was lower than $3 \%(v / v)$ and $\mathrm{N}_{2}$ content was higher than $50 \%(v / v)$ due to the use of air as oxidizing agent. The syngas had a LHV ranging between $3.6 \mathrm{MJ} / \mathrm{Nm}^{3}$ and $4.6 \mathrm{MJ} / \mathrm{Nm}^{3}$. The resulting biochar contained about $74 \mathrm{wt} . \%$ carbon.

The modeling of a small-scale plant based on a downdraft gasifier and a gas engine connected to the grid using OP is available in literature [75]. The power plant is able to produce $70 \mathrm{~kW}$ of electric power and $110 \mathrm{~kW}$ of thermal power when fuelled with $105 \mathrm{~kg} / \mathrm{h}$ biomass and the gasifier operated in steady state conditions. The LHV of the gas produced in the gasifier was $3.7 \mathrm{MJ} / \mathrm{kg}$. This relative low value was explained by the high air to OP ratio (2.72), which increased the $\mathrm{N}_{2}$ formation, and the high ash content in OP $(8.71 \%)$.

Finally, an experimental and feasibility study of a pilot plant installed in an olive mill located in Andalusia (Spain) for the conversion of olive tree pruning and into electrical and thermal power is described elsewhere [31]. The pilot plant was composed of a downdraft gasifier, gas cooling-cleaning stage and spark ignition engine with a modified carburetor. OP was regarded as a suitable substrate for the downdraft gasifier because of its low moisture and ash content. The cold gas efficiency was in the range $70.7-75.5 \%$ and the OP gasification led to a syngas with a LHV of $4.8 \mathrm{MJ} \mathrm{kg}^{-1}$. The electric efficiency of the gas engine reached $21.3 \%$. Besides, the plant achieved acceptable values for the electric $(15 \%)$ and combined heat and power (almost 50\%) efficiency [31]. As a result, the project investment would provide a whole benefit of around $300,000 €$ (net present value), with a payback period of 5-6 years.

\section{Olive Stones}

Currently, there are two industrial processes that are applied to the olive to obtain food products and that allow the recovery of olive stones in two different ways. Thus, in the olive mills, virgin olive oil is produced and, as a by-product, fragmented endocarps, since in the milling stage the olive is passed through a mill that breaks down the structure of the fruit. On the other hand, whole olive stones are recovered in the pitted table olive processing industries; that is, the endocarp plus the seed. Taking into account that the available volume of fragmented endocarps is much higher than that of whole olive stones, most of the studies carried out on the energy use of this type of biomass have been carried out using the former one. Notwithstanding, most of papers available in literature on olive 
stones do not clearly indicate whether fragmented endocarps or the whole olive stones have been used. Therefore, in this review paper the term olive stones (OS) is indistinctively used for both.

\subsection{Preliminary Treatments: Cleaning and Drying}

The most suitable pathway for the transformation of a lignocellulose material towards a specific product is strongly conditioned by the composition and moisture of the raw material. In the case of fragmented endocarps of olive, attention should be paid to the pulp, a material that is often found with them. According to some authors, the average percentage of pulp in OS is $3 \mathrm{wt.} \%$ [76]. Therefore, a first treatment to be applied to the biomass would aim to remove the pulp fraction, which can be easily achieved by sieving the OS, since an analysis of the particle size distribution showed that most of the fragmented endocarps (91.7 wt.\%) had an average diameter of between $2 \mathrm{~mm}$ and $3.15 \mathrm{~mm}$ [77] and most of the pulp and mineral matter tends to accumulate in a fraction of smaller size $(<1 \mathrm{~mm})$ [76]. A direct consequence of the cleaning of the fragmented endocarps is the decrease in the ash content (from $0.78 \%$ to $0.55 \%$ ) and the increase in the bulk density of the clean biomass (from $721.5 \mathrm{~kg} / \mathrm{m}^{3}$ to $764.2 \mathrm{~kg} / \mathrm{m}^{3}$ ). This can be explained by the fact that the pulp, which is the component with the lowest bulk density $\left(129.8 \mathrm{~kg} / \mathrm{m}^{3},[76]\right)$ and the highest ash content $(5.6 \%,[78])$, remains in the fines fraction.

On the other hand, the fragmented endocarps of olives need to be dried in order to be used in certain applications. The moisture of 15 Spanish samples of OS ranged between $10.2 \%$ and $30.5 \%$, with an average value of 22.3\% [19]. Other authors have reported moistures of 19\% [79] and 23\% [80], and equilibrium moistures of $7 \%$ and $8 \%$, respectively. In a previous work, we reported equilibrium moistures for OS between $9.1 \%$ and $11.5 \%$, calculated at $30{ }^{\circ} \mathrm{C}$ and relative humidity between $43.2 \%$ and $73.1 \%$ [3]. The study of the drying kinetics of OS was addressed in the aforementioned last three references $[3,79,80]$.

\subsection{Biochemical Conversion}

Numerous research works that addressing the biochemical use of the olive stones can be found in literature. OS contain hemicellulose very rich in xylans, a low cellulose fraction but with high crystallinity and a relatively high percentage of lignin [81]. The main products obtained in the biochemical conversion of olive stones are xylitol and bioethanol. Both can be achieved simultaneously in the same fermentation stage using yeasts able to ferment $\mathrm{D}$-xylose to xylitol and D-glucose to ethanol. The common denominator of all the biochemical pathways is the application of several stages (pre-treatment, hydrolysis of polysaccharides, detoxification of hydrolysates, fermentation of sugars, separation of bioproducts...), some of which involve the use of microorganisms or enzymes. Among the pre-treatments described in Section 2.1.1., liquid hot water [82-84], steam explosion [25], organosolv [84] and dilute-acid hydrolysis [18,23,84-86] pre-treatments are the most widely ones applied to olive stones. Different schemes and the ethanol and xylitol yields (when available) achieved by several authors from $1 \mathrm{~kg}$ OS are illustrated in Table 7.

Table 7. Ethanol and xylitol yields obtained from olive stones (OS) using different process schemes.

\begin{tabular}{|c|c|c|c|c|c|c|}
\hline Pre-Treatment & Commercial Enzyme Preparation & Product & Fermentation Yeast & SSF Yeast & Overall Yield (kg/kg OS) & Reference \\
\hline $\begin{array}{c}0.01 \mathrm{M} \mathrm{H}_{2} \mathrm{SO}_{4}, 201^{\circ} \mathrm{C} \text {, } \\
5.2 \mathrm{~min}\end{array}$ & Novozymes Celluclast 1.5 L & $\begin{array}{l}\text { Ethanol } \\
\text { Xylitol }\end{array}$ & $\begin{array}{l}\text { P. tannophilus } \\
\text { P. tannophilus }\end{array}$ & - & 0.122 & [23] \\
\hline${ }^{*} \log R_{0}=4.39$ & Cellulase from T. reesei EC 3.2.1.4 & $\begin{array}{l}\text { Ethanol } \\
\text { Xylitol }\end{array}$ & $\begin{array}{l}\text { P. tannophilus } \\
\text { P. tannophilus }\end{array}$ & - & $\begin{array}{l}\text { NP } \\
\text { NP }\end{array}$ & [82] \\
\hline $\begin{array}{l}0.025 \mathrm{M} \mathrm{H}_{2} \mathrm{SO}_{4} \\
195^{\circ} \mathrm{C}, 5 \mathrm{~min}\end{array}$ & Novozymes Celluclast 1.5 L & $\begin{array}{l}\text { Ethanol } \\
\text { Xylitol }\end{array}$ & $\begin{array}{l}\text { P. tannophilus } \\
\text { P. tannophilus }\end{array}$ & $\begin{array}{l}- \\
-\end{array}$ & $\begin{array}{l}0.103 \\
0.092\end{array}$ & [18] \\
\hline $\begin{array}{c}1.5 \%(w / v) \mathrm{H}_{2} \mathrm{SO}_{4} \\
121^{\circ} \mathrm{C}, 60 \mathrm{~min}\end{array}$ & $\begin{array}{l}\text { Novozymes Celluclast } 1.5 \mathrm{~L} \text { and } \\
\text { Novozymes } 188\end{array}$ & Ethanol & - & P. tannophilus & 0.068 & [86] \\
\hline Organosolv, $220^{\circ} \mathrm{C}$ & - & Ethanol & - & S. cerevisiae & 0.131 & [84] \\
\hline
\end{tabular}

${ }^{*}$ Liquid hot water; $\mathrm{NP}=$ not provided. 
The overall process is fairly expensive and, therefore, the biochemical conversion of OS would only be economically viable if, in addition of products with low sale price (in relation to their production process), such as bioethanol or furfural [87], products with very high-added value were obtained, such as antioxidants [26], oligosaccharides [88] or other bioactive molecules. In this sense, the integrated production of xylitol, furfural, ethanol and poly-3-hydroxybutyrate from OS within the biorefinery concept, and a cogeneration system for producing bioenergy from the solid residues resulting from the obtaining of these products has been described [89]. On the other hand, an integrated biorefinery concept for OS management is available in literature, composed of supercritical fluid extraction to recover polyphenols, followed by pyrolysis of the solid to produce bio-renewable fuels and, finally, activation of the biochar to yield high surface area adsorbents for heavy-metals removal from water [90].

In a recent article, we described the fractionation of OS using dilute-sulphuric-acid pre-treatment at high temperature $\left(201{ }^{\circ} \mathrm{C}\right)$ followed by, on one hand, the enzymatic hydrolysis of the pre-treated solids and, on the other hand, the detoxification of the liquid prehydrolysate by means of vacuum distillation. In this way, both the enzymatic hydrolysate, rich in D-glucose, and the detoxified acid prehydrolysate, rich in D-xylose, were easily fermented with $P$. tannophilus to bioethanol and xylitol. The mass balance for the complete ethanol production process is illustrated in Figure 10.

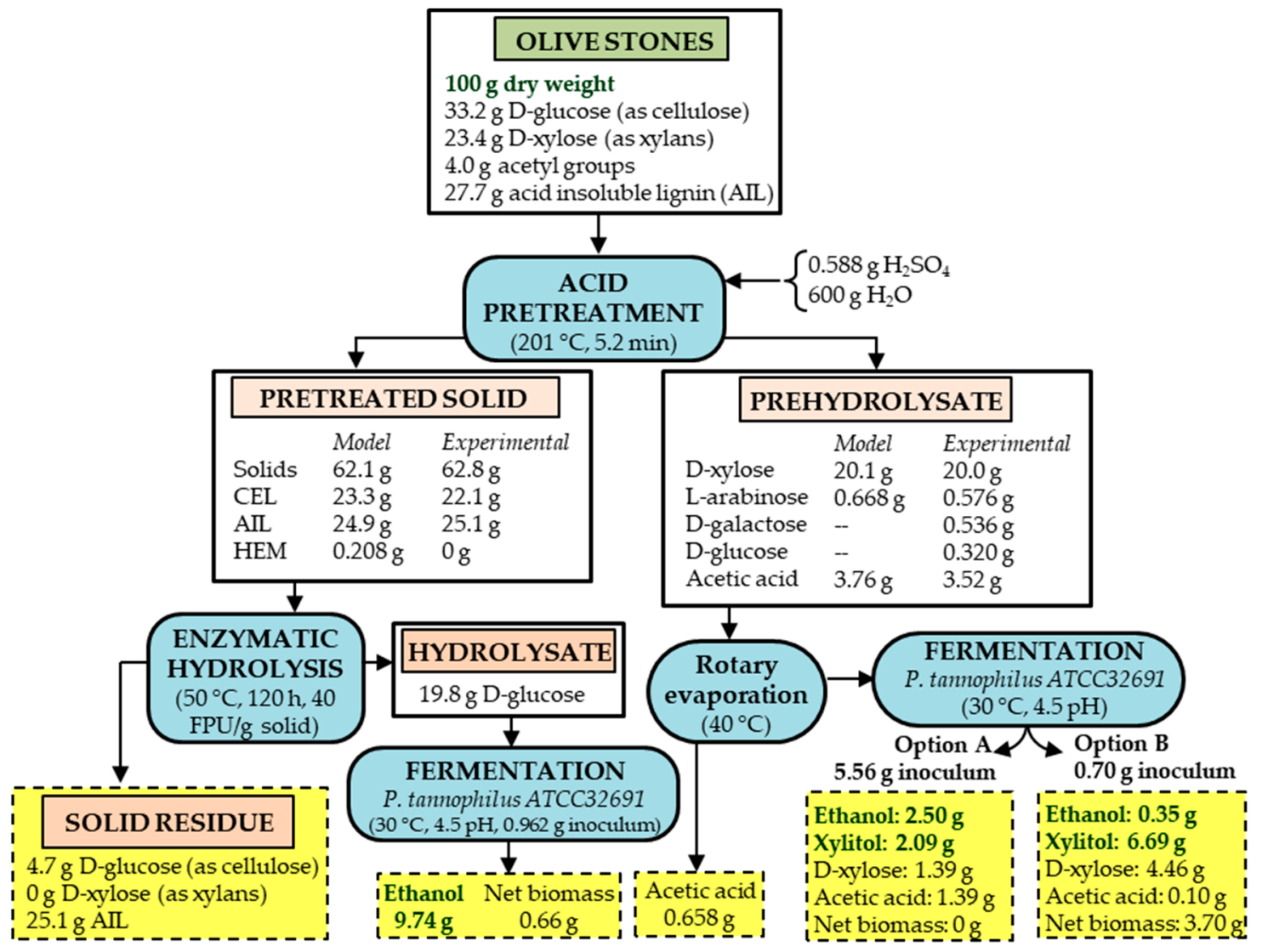

Figure 10. Mass macroscopic balance for the ethanol production flowsheet composed of dilute-acid pre-treatment of OS, enzymatic hydrolysis of pre-treated solids, detoxification with rotary evaporator and fermentation of hydrolysates using P. tannophilus. Reproduced with permission from Cuevas et al., Processes; published by MDPI, 2020 [23].

\subsection{Thermochemical Conversion of Olive Stones}

Among the thermochemical treatments that have been applied to OS, torrefaction, pyrolysis, combustion and gasification can be highlighted. 


\subsubsection{Torrefaction}

Torrefaction is a process that takes place under a non-oxidizing atmosphere through heating biomass to maximum temperatures of the order of $300{ }^{\circ} \mathrm{C}$. In this way, improvements in the energy characteristics of the resulting solids can be achieved such as reduction of the moisture content, increase in calorific value, and improvement of the subsequent pelletizing process [91,92].

Torrefaction can be conducted in an aqueous (wet torrefaction or hydrothermal carbonization) or dry (dry torrefaction) environment. A study on the rapid hydrothermal carbonization of OS at temperatures between $175{ }^{\circ} \mathrm{C}$ and $250^{\circ} \mathrm{C}$ pointed out that the solid residue (hydrochar) obtained at $225^{\circ} \mathrm{C}-10 \mathrm{~min}$ had the highest $\mathrm{HHV}(23.4 \mathrm{MJ} / \mathrm{kg})$, energy efficiency $(74.7 \%)$ and comprehensive combustibility index $\left(6.19 \times 10^{-7} \mathrm{~min}^{-2}{ }^{\circ} \mathrm{C}^{-3}\right)$ [93]. Furthermore, the short-time hydrothermal carbonization caused an increase in the hydrophobic capacity of the hydrochar, which contributes to improving the microbial stability of the material. These authors [93] also indicated that the hydrothermal carbonization has a greater capacity than pyrolysis to eliminate the OS components with lower calorific value (extractives and hemicelluloses) at low temperatures from the raw material.

On the other hand, the effect of the biomass to water ratio (1.1-12.3\%), temperature $\left(150-250{ }^{\circ} \mathrm{C}\right)$, and residence time $(3.2-36.8 \mathrm{~h})$ on the hydrothermal carbonization of OS has been investigated. The HHV ranged from $22.2 \mathrm{MJ} / \mathrm{kg}$ to $29.59 \mathrm{MJ} / \mathrm{kg}$, being the maximum HHV achieved at $230{ }^{\circ} \mathrm{C}-30$ $\mathrm{h}$ [94]. In relation to dry torrefaction, the optimal conditions found for OS were obtained at 278 ${ }^{\circ} \mathrm{C}-15 \mathrm{~min}$ and resulted in a solid product with $68 \%$ volatile matter, $29 \%$ fixed carbon, and $23.4 \mathrm{MJ} / \mathrm{kg}$ HHV [95].

\subsubsection{Pyrolysis}

Pyrolysis of olive stones is a promising technology for the production of renewable energy since it produces a gas with medium calorific value and byproducts (biochar and tar) which can be used to provide more energy to the process.

The thermogravimetric analyses applied to OS under inert atmosphere are of great interest to understand the pyrolysis of this biomass. The main weight losses in dry OS occur between $200{ }^{\circ} \mathrm{C}$ and $400{ }^{\circ} \mathrm{C}$. Two large peaks are highlighted in the DTG curves. The first in the temperature range $264-323{ }^{\circ} \mathrm{C}$ and the second in the range $327-378{ }^{\circ} \mathrm{C}$, which would correspond, respectively, to the decomposition of hemicellulose and cellulose $[29,95,96]$. Weight losses that take place above $400{ }^{\circ} \mathrm{C}$ would produce a long tail in the thermogravimetric curve which correspond to the slow process of lignin decomposition.

Regarding the products yield, the pyrolysis of OS at $600{ }^{\circ} \mathrm{C}-30 \mathrm{~min}$ generated $44.2 \mathrm{wt} . \%$ syngas, $24.9 \mathrm{wt} . \% \mathrm{tar}, 14 \mathrm{wt} . \%$ water and $17.0 \mathrm{wt} . \%$ biochar [97]. The resulting gas was rich in $\mathrm{H}_{2}(29.5 \% \mathrm{v} / \mathrm{v})$, $\mathrm{CO}(31.5 \% v / v)$ and $\mathrm{CH}_{4}(20.5 \% v / v)$, with LHV of $16.0 \mathrm{MJ} / \mathrm{kg}$. Notwithstanding, other authors, when studying the same process with the same raw material and testing temperatures of up to $900{ }^{\circ} \mathrm{C}$, were unable to achieve syngas yields greater than $25 \mathrm{wt} . \%$ related for any of the temperatures tested [95]. Thus, the gas, liquid (tar + water) and biochar fractions were $20.2 \mathrm{wt} . \%, 50.3 \mathrm{wt} . \%$ and $29.5 \mathrm{wt} . \%$, respectively, at $500{ }^{\circ} \mathrm{C}-15 \mathrm{~min}$ [95]. The previous percentages are similar to those found in other studies when olive stones were pyrolyzed at $550{ }^{\circ} \mathrm{C}-15 \mathrm{~min}$ : $35 \mathrm{wt}$.\% biochar and $55 \mathrm{wt}$ \% liquid fraction [29]. In that study, the pyrolysis gas formed at $600{ }^{\circ} \mathrm{C}$ was composed of $17 \% v / v$ methane and over $10 \% v / v$ of both carbon monoxide and hydrogen. The significant deviations in the products yield data available in literature highlight the complexity of the pyrolysis process of OS, which is affected, among others, by factors such as particle size or mineral content [98]. Several studies have demonstrated that other biochar parameters such the actual and bulk densities are strongly affected by pyrolysis, which present minimum values for temperatures in the range $400-500{ }^{\circ} \mathrm{C}[95,99]$. 
As the pyrolysis temperature increases, the biochar produced from OS contains less oxygen and more carbon, which results in an increase in its calorific value (for example, $\mathrm{HHV}=31.1 \mathrm{MJ} / \mathrm{kg}$ at $900{ }^{\circ} \mathrm{C}$ ) [95]. Besides, an increase of the temperature during biomass carbonization decreases the biochar reactivity, with higher ignition and burnout temperatures related to the decrease of volatile matter content [99]. The reactivity of the biochars obtained from five biomasses, including OS, can be found elsewhere [100].

Finally, apart from combustion, the biochar generated from olive stones could be used as hydroponic growing medium [101] or, after its activation [102], as adsorbent of different chemical compounds $[103,104]$, in the manufacture of battery electrodes $[105,106]$, etc.

\subsubsection{Gasification}

The air gasification of OS in a $5 \mathrm{~kW}$ bench scale, bubbling fluidized bed gasifier produced a medium heating value gas $\left(\mathrm{LHV}=6.54 \mathrm{MJ} / \mathrm{Nm}^{3}\right)$. The maximum $\mathrm{H}_{2}$ and $\mathrm{CO}$ concentrations $(24 \% v / v$ and $14.3 \% v / v$, respectively) were obtained at $750^{\circ} \mathrm{C}$ and an equivalence ratio (ER, under stoichiometric amount of air inserted into the reactor to that necessary for complete combustion) of 0.2 [33]. The use of a $150 \mathrm{~kW}$ bubbling-fluidized-bed gasifier with $\mathrm{ER}=0.22$ led to a syngas with $12 \% v / v$ both $\mathrm{H}_{2}$ and $\mathrm{CO}\left(\mathrm{LHV}=5.31 \mathrm{MJ} / \mathrm{Nm}^{3}\right)$ [107]. These authors also pointed out bed agglomeration problems due to the partial ash melting as a consequence of its high potassium content. Notwithstanding, these results improve those obtained in the gasification of OS in a countercurrent fixed-bed gasifier [108]. For instance, a gas containing $6.4 \% v / v \mathrm{H}_{2}$ and $26 \% v / v \mathrm{CO}\left(\mathrm{HHV}=4.8 \mathrm{MJ} / \mathrm{Nm}^{3}\right)$ was achieved for ER $=0.22$ in the countercurrent fixed-bed gasifier. The latter study concluded that olive husk gasification is a more complex process than wood gasification owing to non-uniform flow distribution across the high density bed and partial ash agglomeration. ER values of 0.31 , much higher than those previously described, were used in the gasification of OS in a downdraft gasifier to obtain a syngas with $16 \% v / v$ $\mathrm{H}_{2}$ and $22.8 \% v / v \mathrm{CO}$ [31]. The gasification of OS with high temperature steam $\left(750-1050{ }^{\circ} \mathrm{C}\right)$ has also been investigated [109]. This process allowed obtaining a syngas with notably high LHV $\left(13.6 \mathrm{MJ} / \mathrm{Nm}^{3}\right)$ along with a biochar that contained $79 \mathrm{wt} . \%$ fixed carbon, which enables it for further reuses for energetic and agriculture purposes. This type of gasification also makes it possible to considerably reduce tar production [109].

Finally, a $100 \mathrm{~kg} / \mathrm{h}$ downdraft gasifier system was used to produce clean synthesis gas production from OS in densified forms [110]. An average of $2.5 \mathrm{Nm}^{3}$ of product syngas per $\mathrm{kg}$ OS with a calorific value ranging from $4.5 \mathrm{MJ} / \mathrm{Nm}^{3}$ to $5.0 \mathrm{MJ} / \mathrm{Nm}^{3}$ was achieved, reaching over $97 \%$ conversion of carbon to product gas. A prototype of downdraft gasification system $\left(70 \mathrm{~kW}_{\mathrm{e}}-245 \mathrm{~kW}_{\mathrm{th}}\right)$ combined with a gas engine was assayed for OS [111]. The prototype gasification system consisted of feeding system, hopper, reactor and gas cleaning and cooling system, producing a syngas with an average HHV of 16.1 MJ $/ \mathrm{Nm}^{3}$. The authors concluded that this prototype produced a good quality gas from OS with an electric efficiency of $16.1 \%$. In a later work of these authors, the downdraft gasifier was coupled to a gas engine connected to the grid and fuelled with olive stones [75]. The system provided $70 \mathrm{~kW}_{\mathrm{e}}$ and $110 \mathrm{~kW}_{\text {th }}$ with a consumption of $105 \mathrm{~kg} / \mathrm{h}$ OS. The LHV of the gas produced in the gasifier was $5.1 \mathrm{MJ} / \mathrm{kg}$. The electric efficiency and the overall efficiency of the small-scale plant were $14 \%$ and $36 \%$, respectively.

\subsubsection{Combustion}

Combustion is currently the most important application of OS. Thus, in Spain there are a large number of facilities that burn OS to produce thermal energy in industries, public buildings, neighborhood communities and private homes [112].

The combustion of olive stones can be studied by means of thermogravimetry under oxidizing atmosphere. From the thermogravimetric data it can be verified that there are two different combustion stages. The first stage corresponds to the oxidation of the volatile matter removed from the solid at low relative temperatures and can be clearly observed in a differential thermogravimetric analysis (DTG 
analysis) in the peaks found in the range $200-400{ }^{\circ} \mathrm{C}$, which are related to the combustion of the volatile matter and the breakdown of hemicellulose and cellulose $[93,99]$. To be specific, the decomposition of hemicellulose occurs from $220^{\circ} \mathrm{C}$ to $315^{\circ} \mathrm{C}$ while the breakdown of cellulose takes place between $320^{\circ} \mathrm{C}$ and $400{ }^{\circ} \mathrm{C}$. The second stage consists of the heterogeneous combustion of the char obtained from the pyrolysis of the polysaccharides and lignin. The two DTG peaks for those two reactions are in the range $400-600{ }^{\circ} \mathrm{C}$.

The combustion of OS in fixed bed has been studied by several authors [113]. Besides, the combustion process of three olive-tree-derived biomasses (OS, pulp and residual olive pomace) was compared and the best results were achieved with OS, obtaining the lowest emission levels of unburned hydrocarbons and the highest efficiency (91.1\%) [78]. The combustion of different biomasses in a mural boiler used for domestic heating $(11.6 \mathrm{~kW})$ was also studied. The authors showed that the use of OS pellets, characterized by lower percentages of sulphur and nitrogen contents, led to a significant decrease in $\mathrm{NOx}$ and $\mathrm{SO}_{2}$ emissions [114]. Other authors carried out the combustion of OS pellets in a $40 \mathrm{~kW}$ counter-current fixed bed reactor and assessed some combustion parameters. The results achieved with OS pellets were quite similar to those obtained with the standard wood pellets that are used currently in European biomass markets [115].

In relation to the combustion of OS in fluidized bed, a numerical model was developed to calculate the burn-out time of different biomasses [116]. The results were greatly influenced by the temperature of the surrounding gas and, to a lesser extent, by the particle diameter, moisture content of the fuel, and bulk oxygen concentration. The burn-out time of OS reached values between $0.5 \mathrm{~s}$ and $50 \mathrm{~s}$. The combustion of OS was reported to have bed agglomeration problems during combustion, which was related to the high percentage of potassium in the ash and the low melting point of the ash [117]. Thus, ash is generated during the combustion of OS with a high adhesion capacity on surfaces [118]. It was pointed out that $\mathrm{OS}$ combustion ash had an initial deformation temperature of $714^{\circ} \mathrm{C}$, so this biomass has a high tendency to form slag [77]. Ash generated in the combustion of olive stones have been used, with good results, in the production of biopolymers $[119,120]$.

Finally, it can be highlighted that OS have also been used as fuel for combustion together with lignite [121] or animal sludge [122].

\section{Olive Pomace from Olive Mills and Pomace Extracted from Extraction Plants}

Currently, the most important use of olive pomaces involves a thermochemical conversion using a combustion reactor to generate electrical energy. For this use it is necessary to differentiate between olive pomace from olive mills and extracted pomace from pomace extraction plants.

Normally, the olive pomace from the oil mill that arrives to the extraction plant is subjected to a new process of separation of pulp and stone. This pomace with fewer stone fragments is dried using rotary driers until the equilibrium relative humidity $(8-12 \%)$, then it is pelletized (after a previous grinding) and finally subjected to a solvent extraction, obtaining crude pomace oil and a solid residue that is the extracted pomace. The final objective set in any extraction plant is that this extracted pomace contains less than $0.5 \%$ in fat matter. This extracted pomace constitutes an excellent solid biofuel that is used in industrial boilers and in electric power generation industries (Figure 11).

However, if the olive pomace from the oil mill contains a low concentration of residual oil, in some cases, only the olive stone fragments are separated and the rest is dried in the rotary driers. In this case, this dry residue is directly used in the generation of electrical energy similarly to the extracted pomace.

In this last decade, tests are being carried out on the extracted pomace that involve a biochemical conversion aiming to obtaining bioethanol and other products of higher added value, including mannitol and phenolic compounds [123]. Nevertheless, other proposed applications of olive pomaces in which researchers have put more attention are pellets and biodiesel production. 


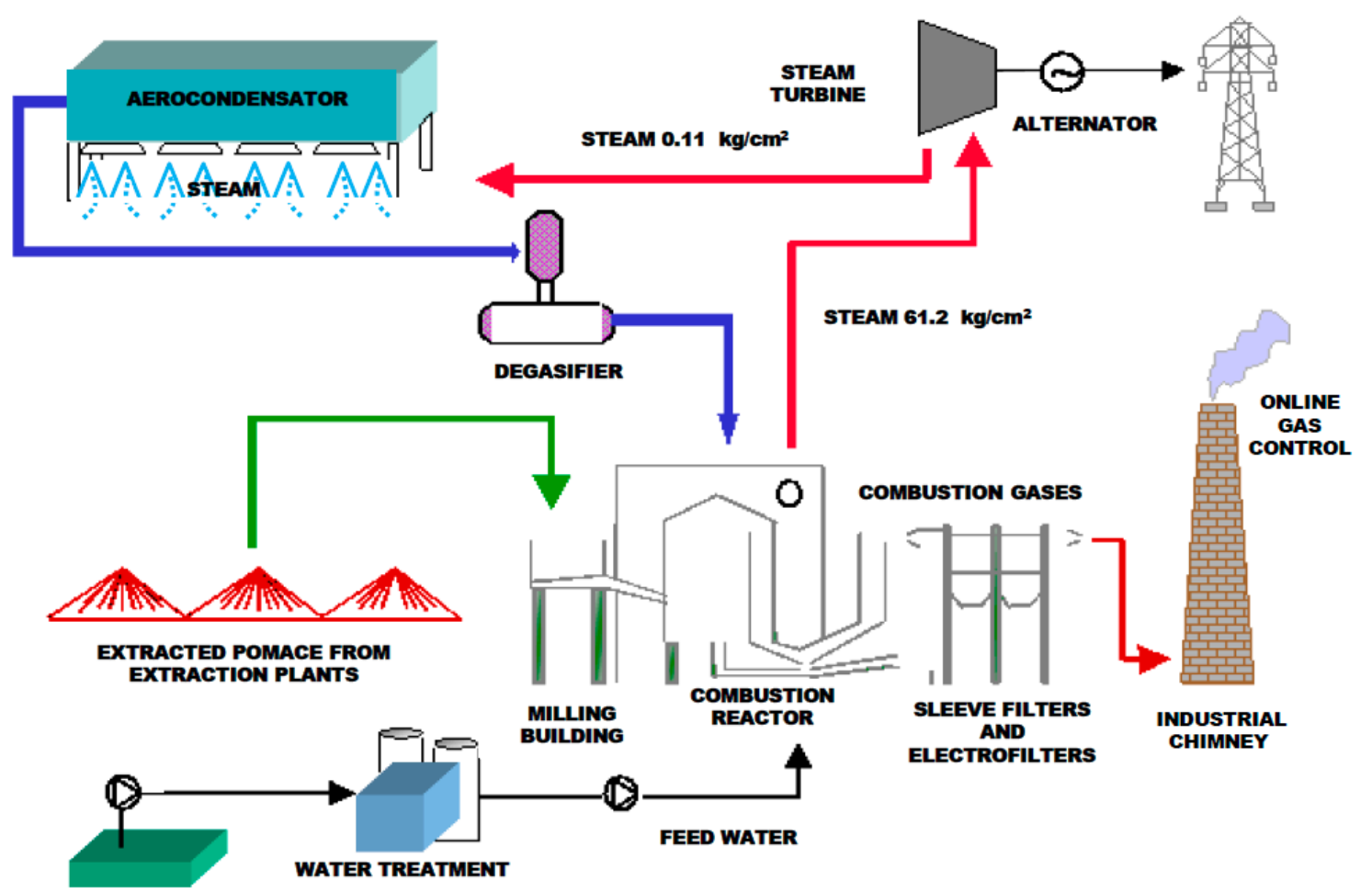

Figure 11. Industrial production of electrical energy using extracted pomace from extraction plants in Spain.

\subsection{Biodiesel Production}

Biodiesel is a promising, renewable, clean-burning fuel composed of long-chain mono alkyl esters from vegetable oils or animal fats through an esterification process typically carried out with methanol and $\mathrm{NaOH}$ as catalyst [124]. Biodiesel can also be obtained from agri-food residues (non-food biomass) such as olive pomace or waste cooking oils, constituting the second generation biodiesel, and from algae, bacteria, filamentous fungi and oil yeasts constituting the third generation biodiesel [125].

Similarly to olive oil, the main fatty acid present in olive pomace is oleic acid. The oil extracted from olive pomace can thus be used for the production of biodiesel through an esterification/transesterification process. Several authors have studied the optimal conditions for producing biodiesel from olive pomace, varying the type of oil extraction, alcohol to oil molar ratio, working temperature, type of catalyst, type of reactor and residence time for both esterification and transesterification. In some cases, the phenolic compounds present in olive pomace have been removed by steam-explosion [126] while in others they have been added to biodiesel to enhance both oxidation and microbial stability of the biofuel during storage [127]. Table 8 summarizes the main schemes available in literature for biodiesel production from olive pomace and the content in fatty acid methyl esters of the produced biodiesels. All these processes were performed in batch reactors. In some of the schemes there was a previous oil extraction while in others the olive pomace was directly subjected to esterification/transesterification. As illustrated in Table 8, the main problem of producing biodiesel from olive pomace is the low overall yields ( $\mathrm{kg}$ biodiesel $/ 100 \mathrm{~kg}$ olive pomace in dry basis) due to its low content in fat matter (Table 5 ). 
Table 8. Procedures and fatty acid methyl esters (FAME) content achieved in the production of biodiesel from olive pomaces.

\begin{tabular}{|c|c|c|c|c|c|c|c|c|c|c|c|}
\hline \multirow{2}{*}{ Extraction/Solvent } & \multicolumn{4}{|c|}{ Esterification } & \multicolumn{4}{|c|}{ Transesterification } & \multirow{2}{*}{ FAME Content (wt.\%) } & \multirow{2}{*}{ Overall Yield (wt.\%) } & \multirow{2}{*}{ Reference } \\
\hline & Catalyst & MR & $t(\min )$ & $\mathrm{T}\left({ }^{\circ} \mathrm{C}\right)$ & Catalyst & MR & $t(\min )$ & $\mathrm{T}\left({ }^{\circ} \mathrm{C}\right)$ & & & \\
\hline Soxhlet/hexane & 1 wt. $\% \mathrm{H}_{2} \mathrm{SO}_{4}$ & $6: 1$ & 80 & 60 & $1 \mathrm{wt} . \% \mathrm{NaOH}$ & $6: 1$ & 80 & 60 & 98.9 & - & [126] \\
\hline \multirow[t]{2}{*}{ Stirring/hexane } & - & - & - & - & 0.54 wt. $\% \mathrm{KOH}$ & $\begin{array}{l}0.1 \\
1: 2\end{array}$ & 60 & 60 & 94.7 & $4.0 \pm 0.0$ & {$[128]$} \\
\hline & - & - & - & - & 1.3 wt. $\% \mathrm{Ba}(\mathrm{OH})_{2}$ & $5: 1$ & 80 & 65 & 93.4 & - & [129] \\
\hline - & - & - & - & - & $5.8 \mathrm{wt} . \%$ biocatalyst * & $5.3: 1$ & 1440 & 40 & 93.7 & - & [130] \\
\hline Stirring/hexane & $20 \mathrm{wt} . \% \mathrm{H}_{2} \mathrm{SO}_{4}$ & $35: 1$ & 60 & 40 & $0.6 \mathrm{wt} . \% \mathrm{KOH}$ & $9: 1$ & 120 & 60 & 97.8 & $3.8 \pm 1.8$ & [131] \\
\hline Soxhlet/hexane & & - & - & - & 1 wt. $\% \mathrm{NaOH}$ & $9: 1$ & 60 & 60 & 95.5 & $6.6 \pm 1.6$ & [132] \\
\hline- & $3 \mathrm{wt} . \% \mathrm{Zn}$ stearate & $30: 1$ & 30 & 140 & $3 \mathrm{wt} . \% \mathrm{Zn}$ stearate & $30: 1$ & 30 & 140 & 84.1 & - & [133] \\
\hline
\end{tabular}

MR: Methanol to oil molar ratio; ${ }^{*}$ Microbial lipase from Thermomyces lanuginosus immobilized onto polyglutaraldehyde-activated olive pomace powder. 
With regard to the third generation biodiesel, the soap stock from the chemical refining of crude olive pomace oil has been used as carbon source for the growth of several microorganisms used for biodiesel production. In general, filamentous fungi, yeasts and bacteria can contain more than $20 \mathrm{wt} . \%$ lipids. The problem for the cultivation of these microorganisms is the carbon source, which is usually quite expensive. The use of agro-industrial waste as carbon source, such as the soap stock obtained from the neutralization with $\mathrm{NaOH}$ during the refining of olive pomace oil, can greatly reduce its cost. For instance, 6 types of oleaginous yeasts showed lipid content between $60.16 \%$ and $64 \%$ when using ammonia as nitrogen source and soap stock from olive pomace oil chemical refining as carbon source [134]. The triglycerides produced had a high oleic content. The fatty acid composition of these yeasts was very similar to the composition of vegetable oils, mainly olive oil and soybean oil. In another study, lactose, oleic acid, maltose, D-xylose, D-galactose, glycerol, D-glucose, sucrose and residues such as soap stock from soybean oil chemical refinement, wheat bran, soap stock from olive pomace oil chemical refinement and waste cooking oil were used as carbon sources for the growth of the fungus Fusarium verticillioides [135]. This fungus produces oil with a major content in palmitic, oleic and linoleic acids. After studying the effects of various parameters such as nitrogen source, carbon source, $\mathrm{pH}$ and temperature, these authors stated that the fungus can not only grow on the low-cost carbon sources but also the produced lipids can be used as a potential feedstock for biodiesel production. Similarly, glucose, glycerol, soap stock from soybean oil chemical refinement, wheat bran, soap stock from olive pomace oil chemical refinement and waste cooking oil were used as carbon source for the fungus Mucor circinelloides [136]. The carbon source influenced the degree of unsaturation of produced lipids. Furthermore, it was demonstrated that the use of soap stock from soybean oil chemical refinement, waste cooking oils and soap stock from olive pomace oil chemical refinement as carbon source for $M$. circinelloides improved lipid yield and the lipid content [136].

\subsection{Anaerobic Digestion}

As stated in Section 2.2, the anaerobic digestion of olive pomaces has been investigated. Biological materials with high humidity and adequate biodegradability can be subjected to an anaerobic digestion process to generate a methane-rich biogas [137], which could be used in various combustion equipment. The wet pomaces produced in the olive mills fulfil these two requirements, although their high lignin content entails a lower digestibility in relation to other organic materials. For this reason, researches have focused on mixing wet pomaces from olive mills with other organic materials, such as olive mill wastewater [138], pig slurry [139], cow slurry and apple pulp [140], or food waste [141], to improve its biodegradability.

The application of different types of pre-treatment on wet pomace would be another possibility to improve methane production. Thus, methane production was enhanced by subjecting olive pomace to hydrothermal pre-treatment at $180^{\circ} \mathrm{C}$ for $3 \mathrm{~h}$ [142]. The pre-treatment provoked a partial breakage of the polymers of the material, which improved its biodegradability. On the other hand, the effects of microwave, ultrasound and alkaline pre-treatments on olive pomace properties and its biomethane potential by anaerobic digestion was researched [143]. The alkaline pre-treatment at room temperature showed a positive effect on fiber degradation and lipid solubilisation as well as the best impact on methane production.

\subsection{Pellets Production}

Olive pomace is an olive mill by-product regarded as a potential raw material for densified biomass products. Notwithstanding, pellets from olive pomace presents out of limits values of nitrogen, which it is a hindrance. To overcome this problem, pellets of mixtures of olive pomace (from 2- and 3-outlet decanters), once dried, and olive -pruning debris were manufactured [144]. The best blends in terms of physical, chemical and mechanical characteristics, and of potential to be used as fuel for combustion and gasification were $75 \%$ OP and $25 \%$ olive pomace from 2 -outlet decanter, and $50 \%$ OP and $50 \%$ olive pomace from 3 -outlet decanter. 
A study of the physico-chemical characteristics of olive pomaces demonstrated that both olive pomace from olive mills and pomace extracted from extraction plants were suitable to be combined with the residues of the sawmills of Pinus radiata and Pinus Populus spp. for pellet formation [145]. These authors performed a comparative cost analysis with traditional pellets from Pinus radiata to assess the profitability of the pellets produced, which showed that profitability increased by $11 \%$ mainly due to the decrease in acquisition, sawing and transportation costs. In addition, it was pointed out that the produced pellets could decrease $\mathrm{CO}_{2}$ emissions by $5.0 \%\left(78,780 \mathrm{t} \mathrm{CO}_{2}\right.$ per year). The most profitable and environmental friendly pellet was that obtained from pomaces from extraction process with two-outlet decanter and Pinus radiata in 90/10 (wt.\%) ratio [145].

Finally, pellets produced from olive mill wastewater and extracted pomace (obtained from olive pomace from 3-outlet decanter after the second extraction of the 3-5\% of residual oil) have been investigated [146]. To be specific, these authors studied 3 pellets samples: extracted pomace, extracted pomace impregnated with olive mill wastewater, and pine sawdust impregnated with olive mill wastewater. The HHV of these pellets were similar to those of other biomasses, being the pellets produced from impregnated extracted pomace the ones with the highest LHV (19.8 MJ/kg) [146].

\subsection{Wet Torrefaction}

As shown in Table 5, the moisture and volatile matter of olive pomace issued from 2-oulet decanter is between $75 \%$ and $85 \%$, which is a hindrance for direct combustion. Therefore, to enhance the energy production from olive pomace, wet torrefaction could be applied to overcome this limitation. It has been demonstrated that torrefaction can improve the carbon content, heating value, ash content and dewatering properties of olive pomace [147]. Thus, the LHV of raw olive pomace was $24.8 \mathrm{MJ} / \mathrm{kg}$ while that of the resulting hydrochar from torrefaction at $225^{\circ} \mathrm{C}$ for $24 \mathrm{~h}$ was $31.4 \mathrm{MJ} / \mathrm{kg}$. Besides, the hydrochars became more hydrophobic, allowing physical dewatering to occur easier and leading to a decrease of the moisture of the hydrochars. As a result, the moisture content decreased from over $70 \%$ to less than $30 \%$ and ash content was far lower than the initial ash content of the olive pomace [147].

\subsection{Pyrolysis}

Fast pyrolysis coupled with steam gasification of latter aforementioned pellets in Section 4.3, produced from olive mill wastewater and extracted olive pomace, have been assessed [146]. The percentage of char obtained in the three assayed pellets after pyrolysis was practically the same, being between $17 \%$ and $18 \%$. Results showed that the highest pyrolysis time at $850{ }^{\circ} \mathrm{C}$ was obtained for the pellets obtained from the impregnation of the olive mill wastewater on the extracted olive pomace (154 s), while they were comparable for the two other pellets (104 s and $114 \mathrm{~s}$, respectively). Besides, the pyrolysis rate of the impregnated extracted pomace pellets was significantly affected by the temperature in the range of $750-950{ }^{\circ} \mathrm{C}$. Such behavior was attributed by the authors to the presence of organic compounds in the impregnated olive pomace, such as polyphenols [146].

\subsection{Gasification}

The steam gasification at $850{ }^{\circ} \mathrm{C}$ under $20 \% \mathrm{H}_{2} \mathrm{O} / 80 \% \mathrm{~N}_{2}$ with a flow rate of $13 \mathrm{dm}^{3} / \mathrm{min}$ of the resulting biochars from the pyrolysis of aforementioned pellets produced from olive mill wastewater and extracted olive pomace showed that impregnated olive pomace pellets achieved lower gasification time (755 s) than olive pomace pellets (830 s) [146]. The authors pointed out that metals present in the olive mill wastewater produced a catalytic effect in the gasification.

Finally, the gasification of pellets and the resulting charcoals from the pyrolysis in a fixed bed reactor of olive pomaces and pine sawdust under different water steam to nitrogen percentages $(10 \%$, $20 \%$ and $30 \% v / v)$ atmospheres at different temperatures $\left(750{ }^{\circ} \mathrm{C}, 800{ }^{\circ} \mathrm{C}, 820{ }^{\circ} \mathrm{C}, 850{ }^{\circ} \mathrm{C}\right.$ and $\left.900{ }^{\circ} \mathrm{C}\right)$, using a macro-thermogravimetric equipment, resulted in a $\mathrm{H}_{2}$-enriched syngas [148]. The pellets and biochars assayed were made of $100 \%$ pine sawdust, $50 \%$ pine sawdust and $50 \%$ olive pomace extracted from extraction plants, $50 \%$ pomace extracted from extraction plants and $50 \%$ olive mill wastewater, 
and $100 \%$ pomace extracted from extraction plants. The rate of conversion improved in pellets with olive mill wastewater, perhaps due to the content in $\mathrm{K}, \mathrm{Ca}$ and $\mathrm{Na}$.

\section{Biofuels from Olive Biomass. Potential Application in Engines}

Bioethanol offers numerous advantages over sophisticated fossil fuels, with the most significant being without doubt the environmental advantages. Bioethanol can allow a better oxidation of hydrocarbons in gasoline blends, which can greatly reduce the amounts of greenhouse gas emissions into the atmosphere. However, the lower heating value $(6381.45 \mathrm{kcal} / \mathrm{kg}$ at ambient temperature) and comparably higher production cost (1.16 euro/ $\mathrm{dm}^{3}$ from lignocellulose biomass) hurdles its widespread application [149]. Thus, the energy generated from ethanol is only approximately two-thirds about that generated from gasoline, so engine consumption increases (in litres per $100 \mathrm{~km}$ ).

Beyond the environmental benefits, the production of bioethanol from olive biomass would contribute to the development of the rural economy and the maintenance of jobs in the olive mill sector now that rural depopulation is so important. It would not only be a solution towards a new low-carbon.

On the other hand, power and torque do not decrease despite the fact that LHV of bioethanol is lower than that of fossil fuels. In some cases, power and torque even increase along with thermal efficiency for the same operating conditions. One explanation for this phenomenon is that the temperature for bioethanol self-ignition is higher than that of gasoline and diesel, as well as its heat of vaporization and octane number.

With respect to emissions produced by combustion, the use of bioethanol in engines shows a reduction in $\mathrm{CO}$ and unburned emissions, with an increase in the $\mathrm{CO}_{2}$ emitted into the environment, mainly because ethanol is a fuel that already incorporates oxygen in the process and facilitates complete combustion. The $\mathrm{CO}_{2}$ produced has no direct effect as a greenhouse gas considering the complete carbon cycle, since it comes from the combustion process of a fuel which raw material is biomass.

NOx emissions are directly related to engine operating conditions, especially temperature. However, it is difficult to predict the trend of NOx emissions when using bioethanol from olive biomass since there is no pre-established relationship between the fuel used and the mentioned parameters. On the other hand, in engines with constant pressure cycle or constant volume cycle, particulate emissions decrease as the proportion of ethanol in the mixture increases [150]. In addition, unburned bioethanol residues can occur in the intake and exhaust manifolds. It is also important to highlight unregulated emissions, such as aldehydes, which increase with respect to when gasoline is used.

With regard to biodiesel, it is usually found mixed with commercial diesel in varying percentages (between $5 \%$ and $30 \%$ ), as well as 100\% biodiesel in some cases. The presence of biodiesel in the fuel affects its physical and chemical properties. Biodiesel is a much more suitable fuel than vegetable oils for use in current diesel engines, due especially to its lower viscosity, lower cold filter plugging point, lower carbonaceous residue and higher cetane number. Therefore, biodiesel from olive pomace (i.e., biodiesel from the oil extracted from olive pomace, thus involving an extraction stage) would be more suitable for diesel engines than, for instance, olive oil. Nevertheless, biodiesel from olive pomace would have to compete with that from waste cooking oils. Biodiesel production from waste cooking oils has a huge development and its production using different reactors and the study of the exhaust gases are available in literature [124]. Furthermore, the overall biodiesel yields from raw material are far higher from waste cooking oils than from olive pomace, which are extremely low (Table 8).

In spite of these drawbacks, the combustion characteristics of biodiesel obtained from olive pomace oils have been studied at laboratory scale, without taking into account the economic feasibility [151-153]. In one of these works, biodiesel from olive pomace oil was mixed with diesel at volumetric ratios of $5 / 95,7 / 93,10 / 90$ and 100/0 [153]. The engine performance (power, torque, specific fuel consumption) and combustion characteristic in cylinder (in-cylinder pressure values) of these mixtures were assessed. In another work, brake-specific fuel consumption and main exhaust emissions ( $\mathrm{NOx}, \mathrm{SO}_{2}$ and $\mathrm{CO}$ ) using three different load conditions $(50 \%, 75 \%$ and $100 \%)$ were evaluated using different blends of biodiesel from olive pomace oil and diesel, aiming of selecting the optimal operating conditions of 
a diesel engine [152]. Finally, exhaust emissions, noise and sound quality of a direct injection diesel engine using blends of biodiesel from olive pomace oil and diesel were studied at several steady-state engine operating conditions [151]. The increase of biodiesel in the blends lowered CO emissions and reduced air and noise pollution while improving engine sound quality. By contrast, NOx emissions increased, keeping fuel consumption constant. These authors found that cetane number exhibited a stronger effect over noise production than bulk modulus, whereas the reverse effect was found concerning NOx emissions.

In summary, the use of biofuels in alternative internal combustion engines has both advantages and disadvantages in their operation. Even so, the future of biofuels is promising and in a short period of time their use will be an increasingly solid and favourable option.

\section{Conclusions}

At present, the solely actual energetic application of the three olive orchard by-products described in this paper, i.e., olive-tree pruning, olive stones and olive pomaces (including olive pomace from olive mills and olive pomace extracted from extraction plants), is their combustion in boilers either in small industries or households. Among these by-products, the extracted pomace (issued from pomace extraction plants) is the most used at industrial scale. It is regarded as an excellent solid biofuel for is used in industrial boilers and in electric power generation industries.

As previously stated, olive tree prunings and olive stones could be used for bioethanol production. The most promising by-product for bioethanol production could be the olive-pruning debris, since its $\mathrm{HHV}$ is low, and thus it is the worst raw material for combustion, and it has the largest percentage of hollocelullose, mainly cellulose. In addition, due to its low lignin content, the pre-treatment, enzymatic hydrolysis and fermentation are easier to be carried out. Nevertheless, second generation bioethanol is not economically feasible nowadays at industrial scale. Reducing the number of stages (as opposed to what can be found in recent literature on laboratory scale researches) and a complete use of sugars from both hemicellulose and cellulose are mandatory. The resulting solid from the raw material at the end of the process, composed mainly by lignin, could be used for pellets production.

Olive stones are nowadays used in small boilers in the own olive mills and in buildings, hotels, shopping centres, etc., around the world. Olive stones have shown some potential for electricity production through gasification. The efficiency could be improved if the syngas is cleaned and then burnt in a turbine. Torrefaction, instead of pyrolysis, would provide a solid with better fuel characteristics for subsequent combustion or gasification with moderate energy expenditure. In spite of their lower hollocelulose content, compared to that of olive-tree pruning, olive stones have provided notable bioethanol yields, so this energetic route should be not discarded in medium term.

Olive pomaces are currently used in Andalusia (Spain) in thermal power stations, and it is envisaged that more plants will be set up in the next years. The biodiesel production from olive pomace is currently being studied at laboratory scale, although an industrial development seems difficult due to its low fat matter content and the high price of olive pomace oil when using directly the oil extracted from olive pomace.

Finally, it should be highlighted that the integral use of wastes and by-products from the Olive Oil Industry must evolve towards the current technological concept of 'Integrated Biorefinery', which means maximum reuse of by-products and wastes through biochemical and thermochemical processes, of greater efficiency and minimal environmental impact, in the production of biofuels (such as bioethanol, biodiesel, biogas and synthetic gas), as well as other products of high added value.

Author Contributions: Section 1 (Introduction): J.F.G.M., S.S. and C.-H.F.; Section 2 (Olive-pruning debris): J.F.G.M.; Section 3 (Olive stones): M.C. and J.F.G.M.; Section 4 (Olive pomaces): S.S., P.Á.M., J.F.G.M. and M.C.; Section 5 (Biofuels and engines): J.F.G.M., M.T.G., S.S. and C.-H.F.; Section 6 (Conclusions): J.F.G.M. and S.S. All authors have read and agree to the published version of the manuscript.

Funding: This research received no external funding. 
Acknowledgments: Chao-Hui Feng would like to express her gratitude to University of Seville for the mobility grant (VIPPIT-2018-I.3) awarded under the VI Plan Propio de Investigación y Transferencia of the University of Seville. Chao-Hui Feng also wishes to acknowledge the RIKEN's Special Postdoctoral Researcher Program for funding her research career.

Conflicts of Interest: The authors declare no conflict of interest.

\section{References}

1. Feng, C.H.; Wang, W.; Makino, Y.; García-Martín, J.F.; Alvarez-Mateos, P.; Song, X.Y. Evaluation of storage time and temperature on physicochemical properties of immersion vacuum cooled sausages stuffed in the innovative casings modified by surfactants and lactic acid. J. Food Eng. 2019, 257, 34-43. [CrossRef]

2. Feng, C.H.; Makino, Y. Colour analysis in sausages stuffed in modified casings with different storage days using hyperspectral imaging-A feasibility study. Food Control 2020, 111, 107047. [CrossRef]

3. Cuevas, M.; Martínez-Cartas, M.L.; Pérez-Villarejo, L.; Hernández, L.; García-Martín, J.F.; Sánchez, S. Drying kinetics and effective water diffusivities in olive stone and olive-tree pruning. Renew. Energy 2019, 132, 911-920. [CrossRef]

4. Cuevas, M.; Sánchez, S.; Bravo, V.; García, J.F.; Baeza, J.; Parra, C.; Freer, J. Determination of optimal pre-treatment conditions for ethanol production from olive-pruning debris by simultaneous saccharification and fermentation. Fuel 2010, 89, 2891-2896. [CrossRef]

5. The Food and Agriculture Organization. Crops. Available online: http://www.fao.org/faostat/en/\#data/QC/ visualize (accessed on 3 February 2020).

6. Sánchez, S.; Moya, A.J.; Moya, M.; Romero, I.; Torrero, R.; Bravo, V.; San Miguel, M.P. Aprovechamiento del residuo de poda del olivar mediante conversión termoquímica. Ing. Quim. 2002, 391, 184-202.

7. Garcia-Maraver, A.; Rodriguez, M.L.; Serrano-Bernardo, F.; Diaz, L.F.; Zamorano, M. Factors affecting the quality of pellets made from residual biomass of olive trees. Fuel Process. Technol. 2015, 129, 1-7. [CrossRef]

8. Pérez, A.; Martín-Lara, M.A.; Gálvez-Pérez, A.; Calero, M.; Ronda, A. Kinetic analysis of pyrolysis and combustion of the olive tree pruning by chemical fractionation. Bioresour. Technol. 2018, 249, 557-566. [CrossRef]

9. Iáñez-Rodríguez, I.; Martín-Lara, M.Á.; Blázquez, G.; Osegueda, Ó.; Calero, M. Thermal analysis of olive tree pruning and the by-products obtained by its gasification and pyrolysis: The effect of some heavy metals on their devolatilization behavior. J. Energy Chem. 2019, 32, 105-117. [CrossRef]

10. García Martín, J.F.; Sánchez, S.; Bravo, V.; Cruz, N.; Cuevas, M.; Rigal, L.; Doumeng, C. Hidrólisis ácida del residuo de poda de olivo en un reactor de extrusión. Afinidad 2008, 65, 39-44.

11. García, J.F.; Sánchez, S.; Bravo, V.; Rigal, L.; Cuevas, M. Acid hydrolysis of olive-pruning debris for D-xylose production. Collect. Czechoslov. Chem. Commun. 2008, 73, 637-648. [CrossRef]

12. Martínez-Patiño, J.C.; Ruiz, E.; Romero, I.; Cara, C.; López-Linares, J.C.; Castro, E. Combined acid/alkaline-peroxide pretreatment of olive tree biomass for bioethanol production. Bioresour. Technol. 2017, 239, 326-335. [CrossRef] [PubMed]

13. Cara, C.; Ruiz, E.; Ballesteros, M.; Manzanares, P.; Negro, M.J.; Castro, E. Production of fuel ethanol from steam-explosion pretreated olive tree pruning. Fuel 2008, 87, 692-700. [CrossRef]

14. Peinado, S.; Mateo, S.; Sánchez, S.; Moya, A.J. Effectiveness of sodium borohydride treatment on acid hydrolyzates from olive-tree pruning biomass for bioethanol production. Bioenergy Res. 2019, 12, 302-311. [CrossRef]

15. Mateo, S.; Puentes, J.G.; Moya, A.J.; Sánchez, S. Ethanol and xylitol production by fermentation of acid hydrolysate from olive pruning with Candida tropicalis NBRC 0618. Bioresour. Technol. 2015, 190, 1-6. [CrossRef]

16. García, J.F.; Sánchez, S.; Bravo, V.; Cuevas, M.; Rigal, L.; Gaset, A. Xylitol production from olive-pruning debris by sulphuric acid hydrolysis and fermentation with Candida tropicalis. Holzforschung 2011, 65, 59-65. [CrossRef]

17. Mata-Sánchez, J.; Pérez-Jiménez, J.A.; Díaz-Villanueva, M.J.; Serrano, A.; Núñez-Sánchez, N.; López-Giménez, F.J. Statistical evaluation of quality parameters of olive stone to predict its heating value. Fuel 2013, 113, 750-756. [CrossRef] 
18. Saleh, M.; Cuevas, M.; García, J.F.; Sánchez, S. Valorization of olive stones for xylitol and ethanol production from dilute acid pretreatment via enzymatic hydrolysis and fermentation by Pachysolen tannophilus. Biochem. Eng. J. 2014, 90, 286-293. [CrossRef]

19. Mata-Sánchez, J.; Pérez-Jiménez, J.A.; Díaz-Villanueva, M.J.; Serrano, A.; Núñez-Sánchez, N.; López-Giménez, F.J. Development of olive stone quality system based on biofuel energetic parameters study. Renew. Energy 2014, 66, 251-256. [CrossRef]

20. Fernández-Bolaños, J.; Felizón, B.; Heredia, A.; Guillén, R.; Jiménez, A. Characterization of the lignin obtained by alkaline delignification and of the cellulose residue from steam-exploded olive stones. Bioresour. Technol. 1999, 68, 121-132. [CrossRef]

21. Barreca, F.; Fichera, C.R. Use of olive stone as an additive in cement lime mortar to improve thermal insulation. Energy Build. 2013, 62, 507-513. [CrossRef]

22. Rodríguez, G.; Lama, A.; Rodríguez, R.; Jiménez, A.; Guillén, R.; Fernández-Bolaños, J. Olive stone an attractive source of bioactive and valuable compounds. Bioresour. Technol. 2008, 99, 5261-5269. [CrossRef] [PubMed]

23. Cuevas, M.; Saleh, M.; García-Martín, J.F.; Sánchez, S. Acid and enzymatic fractionation of olive stones for ethanol production using Pachysolen tannophilus. Processes 2020, 8, 195. [CrossRef]

24. Martín-Lara, M.A.; Hernáinz, F.; Calero, M.; Blázquez, G.; Tenorio, G. Surface chemistry evaluation of some solid wastes from olive-oil industry used for lead removal from aqueous solutions. Biochem. Eng. J. 2009, 44, 151-159. [CrossRef]

25. Fernández-Bolaños, J.; Felizón, B.; Heredia, A.; Rodríguez, R.; Guillén, R.; Jiménez, A. Steam-explosion of olive stones: Hemicellulose solubilization and enhancement of enzymatic hydrolysis of cellulose. Bioresour. Technol. 2001, 79, 53-61. [CrossRef]

26. Lama-Muñoz, A.; Romero-García, J.M.; Cara, C.; Moya, M.; Castro, E. Low energy-demanding recovery of antioxidants and sugars from olive stones as preliminary steps in the biorefinery context. Ind. Crops Prod. 2014, 60, 30-38. [CrossRef]

27. Pattara, C.; Cappelletti, G.M.; Cichelli, A. Recovery and use of olive stones: Commodity, environmental and economic assessment. Renew. Sustain. Energy Rev. 2010, 14, 1484-1489. [CrossRef]

28. García, G.B.; Calero De Hoces, M.; Martínez García, C.; Cotes Palomino, M.T.; Gálvez, A.R.; Martín-Lara, M.Á. Characterization and modeling of pyrolysis of the two-phase olive mill solid waste. Fuel Process. Technol. 2014, 126, 104-111. [CrossRef]

29. Blanco-López, M.C.; Blanco, C.G.; Martínez-Alonso, A.; Tascón, J.M.D. Composition of gases released during olive stones pyrolysis. J. Anal. Appl. Pyrolysis 2002, 65, 313-322. [CrossRef]

30. Skodras, G.; Grammelis, P.; Basinas, P.; Kakaras, E.; Sakellaropoulos, G. Pyrolysis and combustion characteristics of biomass and waste-derived feedstock. Ind. Eng. Chem. Res. 2006, 45, 3791-3799. [CrossRef]

31. Vera, D.; Jurado, F.; Margaritis, N.K.; Grammelis, P. Experimental and economic study of a gasification plant fuelled with olive industry wastes. Energy Sustain. Dev. 2014, 23, 247-257. [CrossRef]

32. García, R.; Pizarro, C.; Lavín, A.G.; Bueno, J.L. Characterization of Spanish biomass wastes for energy use. Bioresour. Technol. 2012, 103, 249-258. [CrossRef] [PubMed]

33. Skoulou, V.; Koufodimos, G.; Samaras, Z.; Zabaniotou, A. Low temperature gasification of olive kernels in a 5-kW fluidized bed reactor for $\mathrm{H}_{2}$-rich producer gas. Int. J. Hydrog. Energy 2008, 33, 6515-6524. [CrossRef]

34. Di Giovacchino, L. I sottoprodotti della lavorazione delle olive in oleificio. In Tecnologie di Lavorazione Delle Olive in Frantoio; Di Giovacchino, L., Ed.; Tecnica Alimentare: Milano, Italy, 2010; pp. 243-258. ISBN 978-88-481-2554-3.

35. Yang, B.; Boussaid, A.; Mansfield, S.D.; Gregg, D.J.; Saddler, J.N. Fast and efficient alkaline peroxide treatment to enhance the enzymatic digestibility of steam-exploded softwood substrates. Biotechnol. Bioeng. 2002, 77, 678-684. [CrossRef]

36. Zheng, Y.; Zhao, J.; Xu, F.; Li, Y. Pretreatment of lignocellulosic biomass for enhanced biogas production. Prog. Energy Combust. Sci. 2014, 42, 35-53. [CrossRef]

37. Nitayavardhana, S.; Shrestha, P.; Rasmussen, M.L.; Lamsal, B.P.; van Leeuwen, J.H.; Khanal, S.K. Ultrasound improved ethanol fermentation from cassava chips in cassava-based ethanol plants. Bioresour. Technol. 2010, 8, 2741-2747. [CrossRef] 
38. Perrone, O.M.; Colombari, F.M.; Rossi, J.S.; Moretti, M.M.S.; Bordignon, S.E.; Nunes, C.D.C.C.; Gomes, E.; Boscolo, M.; Da-Silva, R. Ozonolysis combined with ultrasound as a pretreatment of sugarcane bagasse: Effect on the enzymatic saccharification and the physical and chemical characteristics of the substrate. Bioresour. Technol. 2016, 218, 69-76. [CrossRef]

39. Martínez-Patiño, J.C.; Gullón, B.; Romero, I.; Ruiz, E.; Brnčić, M.; Žlabur, J.Š.; Castro, E. Optimization of ultrasound-assisted extraction of biomass from olive trees using response surface methodology. Ultrason. Sonochem. 2019, 51, 487-495. [CrossRef]

40. García, A.; González Alriols, M.; Labidi, J. Evaluation of the effect of ultrasound on organosolv black liquor from olive tree pruning residues. Bioresour. Technol. 2012, 108, 155-161. [CrossRef]

41. Ponnusamy, V.K.; Nguyen, D.D.; Dharmaraja, J.; Shobana, S.; Banu, J.R.; Saratale, R.G.; Chang, S.W.; Kumar, G. A review on lignin structure, pretreatments, fermentation reactions and biorefinery potential. Bioresour. Technol. 2019, 271, 462-472. [CrossRef]

42. Peretz, R.; Gerchman, Y.; Mamane, H. Ozonation of tannic acid to model biomass pretreatment for bioethanol production. Bioresour. Technol. 2017, 241, 1060-1066. [CrossRef]

43. Negro, M.J.; Alvarez, C.; Ballesteros, I.; Romero, I.; Ballesteros, M.; Castro, E.; Manzanares, P.; Moya, M.; Oliva, J.M. Ethanol production from glucose and xylose obtained from steam exploded water-extracted olive tree pruning using phosphoric acid as catalyst. Bioresour. Technol. 2014, 153, 101-107. [CrossRef] [PubMed]

44. Barbanera, M.; Buratti, C.; Cotana, F.; Foschini, D.; Lascaro, E. Effect of steam explosion pretreatment on sugar production by enzymatic hydrolysis of olive tree pruning. Energy Procedia 2015, 81, 146-154. [CrossRef]

45. Tortosa, J.F.; Rubio, M.; Gómez, D. Autohidrólisis de tallo de maiz en suspensión acuosa. Afinidad 1995, 52, 181-188.

46. Overend, R.P.; Chornet, E. Fractionation of lignocellulosics by steam-aqueous pretreatments. Philos. Trans. R. Soc. London. Ser. A Math. Phys. Sci. 1987, 321, 523-536.

47. García Martín, J.F.; Cuevas, M.; Bravo, V.; Sánchez, S. Ethanol production from olive prunings by autohydrolysis and fermentation with Candida tropicalis. Renew. Energy 2010, 35, 1602-1608. [CrossRef]

48. García, J.F.; Sánchez, S.; Bravo, V.; Cuevas, M. Autohydrolysis and acid post-hydrolysis of olive-pruning debris. Afinidad 2010, 67, 279-282.

49. Gatt, E.; Rigal, L.; Vandenbossche, V. Biomass pretreatment with reactive extrusion using enzymes: A review. Ind. Crops Prod. 2018, 122, 329-339. [CrossRef]

50. García Martín, J.F.; Sánchez, S.; Cuevas, M. Evaluation of the effect of the dilute acid hydrolysis on sugars release from olive prunings. Renew. Energy 2013, 51, 382-387. [CrossRef]

51. Martínez-Patiño, J.C.; Lu-Chau, T.A.; Gullón, B.; Ruiz, E.; Romero, I.; Castro, E.; Lema, J.M. Application of a combined fungal and diluted acid pretreatment on olive tree biomass. Ind. Crops Prod. 2018, 121, 10-17. [CrossRef]

52. Romero, I.; Moya, M.; Sánchez, S.; Ruiz, E.; Castro, E.; Bravo, V. Ethanolic fermentation of phosphoric acid hydrolysates from olive tree pruning. Ind. Crops Prod. 2007, 25, 160-168. [CrossRef]

53. Ho, M.C.; Ong, V.Z.; Wu, T.Y. Potential use of alkaline hydrogen peroxide in lignocellulosic biomass pretreatment and valorization - A review. Renew. Sustain. Energy Rev. 2019, 112, 75-86. [CrossRef]

54. Sun, Y.; Cheng, J. Hydrolysis of lignocellulosic materials for ethanol production: A review. Bioresour. Technol. 2002, 83, 1-11. [CrossRef]

55. Palmqvist, E.; Grage, H.; Meinander, N.Q.; Hahn-Hägerdal, B. Main and interaction effects of acetic acid, furfural, and p- hydroxybenzoic acid on growth and ethanol productivity of yeasts. Biotechnol. Bioeng. 1999, 63, 46-55. [CrossRef]

56. García, J.F.; Sánchez, S.; García, J. Ethanol from biomass: Application to the olive-pruning debris. In Liquid Fuels: Types, Properties and Production; Carasillo, D.A., Ed.; Nova Science Publishers: Hauppauge, NY, USA, 2012; pp. 239-254. ISBN 9781614704355.

57. Bayrock, D.P.; Ingledew, W.M. Ethanol production in multistage continuous, single stage continuous, Lactobacillus-contaminated continuous, and batch fermentations. World J. Microbiol. Biotechnol. 2005, 21, 83-88. [CrossRef]

58. Sánchez, S.; Bravo, V.; García, J.F.; Cruz, N.; Cuevas, M. Fermentation of D-glucose and D-xylose mixtures by Candida tropicalis NBRC 0618 for xylitol production. World J. Microbiol. Biotechnol. 2008, 24, 709-716. [CrossRef] 
59. Sánchez, S.; Bravo, V.; Castro, E.; Moya, A.J.; Camacho, F. The fermentation of mixtures of D-glucose and D-xylose by Candida shehatae, Pichia stipitis or Pachysolen tannophilus to produce ethanol. J. Chem. Technol. Biotechnol. 2002, 77, 641-648. [CrossRef]

60. Moya, A.J.; Bravo, V.; Mateo, S.; Sánchez, S. Fermentation of acid hydrolysates from olive-tree pruning debris by Pachysolen tannophilus. Bioprocess Biosyst. Eng. 2008, 31, 611-617. [CrossRef]

61. Costa, P.; Dell'Omo, P.P.; La Froscia, S. Multistage milling and classification for improving both pellet quality and biogas production from hazelnut and olive pruning. Ann. Chim. Sci. des Mater. 2018, 42, 471-487. [CrossRef]

62. Messineo, A.; Maniscalco, M.P.; Volpe, R. Biomethane recovery from olive mill residues through anaerobic digestion: A review of the state of the art technology. Sci. Total Environ. 2020, 703, 135508. [CrossRef]

63. Carone, M.T.; Pantaleo, A.; Pellerano, A. Influence of process parameters and biomass characteristics on the durability of pellets from the pruning residues of Olea europaea L. Biomass Bioenergy 2011, 35, 402-410. [CrossRef]

64. Zambon, I.; Colosimo, F.; Monarca, D.; Cecchini, M.; Gallucci, F.; Proto, A.R.; Lord, R.; Colantoni, A. An innovative agro-forestry supply chain for residual biomass: Physicochemical characterisation of biochar from olive and hazelnut pellets. Energies 2016, 9, 526. [CrossRef]

65. Martín-Lara, M.A.; Ronda, A.; Zamora, M.C.; Calero, M. Torrefaction of olive tree pruning: Effect of operating conditions on solid product properties. Fuel 2017, 202, 109-117. [CrossRef]

66. Martín-Lara, M.A.; Blázquez, G.; Zamora, M.C.; Calero, M. Kinetic modelling of torrefaction of olive tree pruning. Appl. Therm. Eng. 2017, 113, 1410-1418. [CrossRef]

67. Zabaniotou, A.; Rovas, D.; Monteleone, M. Management of olive grove pruning and solid waste from olive oil extraction via thermochemical processes. Waste Biomass Valorization 2015, 6, 831-842. [CrossRef]

68. Calahorro, C.V.; Serrano, V.G.; Alvaro, J.H.; García, A.B. The use of waste matter after olive grove pruning for the preparation of charcoal. The influence of the type of matter, particle size and pyrolysis temperature. Bioresour. Technol. 1992, 40, 17-22. [CrossRef]

69. Hidayat, A.; Rochmadi; Wijaya, K.; Nurdiawati, A.; Kurniawan, W.; Hinode, H.; Yoshikawa, K.; Budiman, A. Esterification of palm fatty acid distillate with high amount of free fatty acids using coconut shell char based catalyst. Energy Procedia 2015, 75, 969-974. [CrossRef]

70. Álvarez-Mateos, P.; García-Martín, J.F.; Guerrero-Vacas, F.J.; Naranjo-Calderón, C.; Barrios, C.C.; Pérez Camino, M.D.C.; Barrios, C.C. Valorization of a high-acidity residual oil generated in the waste cooking oils recycling industries. Grasas Aceites 2019, 40, e335. [CrossRef]

71. Bartoli, M.; Rosi, L.; Giovannelli, A.; Frediani, P.; Frediani, M. Characterization of bio-oil and bio-char produced by low-temperature microwave-assisted pyrolysis of olive pruning residue using various absorbers. Waste Manag. Res. 2020, 38, 213-225. [CrossRef]

72. Nilsson, S.; Gómez-Barea, A.; Fuentes-Cano, D.; Haro, P.; Pinna-Hernández, G. Gasification of olive tree pruning in fluidized bed: Experiments in a laboratory-scale plant and scale-up to industrial operation. Energy Fuels 2017, 31, 542-554. [CrossRef]

73. Nilsson, S.; Gómez-Barea, A.; Fuentes-Cano, D.; Campoy, M. Gasification kinetics of char from olive tree pruning in fluidized bed. Fuel 2014, 125, 192-199. [CrossRef]

74. Gallucci, F.; Longo, L.; Santangelo, E.; Guerriero, E.; Paolini, V.; Carnevale, M.; Colantoni, A.; Tonolo, A. Assessment of syngas produced from gasification of olive tree pruning in a downdraft reactor. In Proceedings of the European Biomass Conference and Exhibition Proceedings, Copenhagen, Denmark, 14-18 May 2018.

75. Vera, D.; De Mena, B.; Jurado, F.; Schories, G. Study of a downdraft gasifier and gas engine fueled with olive oil industry wastes. Appl. Therm. Eng. 2013, 51, 119-129. [CrossRef]

76. Sánchez, J.M.; Jiménez, J.A.P.; Villanueva, M.J.D.; Serrano, A.; Núñez, N.; Giménez, J.L. New techniques developed to quantify the impurities of olive stone as solid biofuel. Renew. Energy 2015, 78, 566-572. [CrossRef]

77. Vega-Nieva, D.J.; Ortiz Torres, L.; Míguez Tabares, J.L.; Morán, J. Measuring and predicting the slagging of woody and herbaceous Mediterranean biomass fuels on a domestic pellet boiler. Energy Fuels 2016, 30, 1085-1095. [CrossRef]

78. Miranda, M.T.; Cabanillas, A.; Rojas, S.; Montero, I.; Ruiz, A. Combined combustion of various phases of olive wastes in a conventional combustor. Fuel 2007, 86, 367-372. [CrossRef] 
79. Gómez-de la Cruz, F.J.; Casanova-Peláez, P.J.; Palomar-Carnicero, J.M.; Cruz-Peragón, F. Drying kinetics of olive stone: A valuable source of biomass obtained in the olive oil extraction. Energy 2014, 75, 146-152. [CrossRef]

80. Gómez-De La Cruz, F.J.; Palomar-Carnicero, J.M.; Casanova-Peláez, P.J.; Cruz-Peragón, F. Experimental determination of effective moisture diffusivity during the drying of clean olive stone: Dependence of temperature, moisture content and sample thickness. Fuel Process. Technol. 2015, 137, 320-326. [CrossRef]

81. Coimbra, M.A.; Waldron, K.W.; Selvendran, R.R. Isolation and characterisation of cell wall polymers from the heavily lignified tissues of olive (Olea europaea) seed hull. Carbohydr. Polym. 1995, 27, 285-294. [CrossRef]

82. Cuevas, M.; Sánchez, S.; Bravo, V.; Cruz, N.; García, J.F. Fermentation of enzymatic hydrolysates from olive stones by Pachysolen tannophilus. J. Chem. Technol. Biotechnol. 2009, 84, 461-467. [CrossRef]

83. Cuevas, M.; García, J.F.; Hodaifa, G.; Sánchez, S. Oligosaccharides and sugars production from olive stones by autohydrolysis and enzymatic hydrolysis. Ind. Crops Prod. 2015, 70, 100-106. [CrossRef]

84. Cuevas, M.; Sánchez, S.; García, J.F.; Baeza, J.; Parra, C.; Freer, J. Enhanced ethanol production by simultaneous saccharification and fermentation of pretreated olive stones. Renew. Energy 2015, 74, 839-847. [CrossRef]

85. Cuevas, M.; Saleh, M.; García-Martín, J.F.; Sánchez, S. Influence of solid loading on D-xylose production through dilute sulphuric acid hydrolysis of olive stones. Grasas Aceites 2015, 66, e084.

86. Antonopoulou, G.; Kampranis, A.; Ntaikou, I.; Lyberatos, G. Enhancement of liquid and gaseous biofuels production from agro-industrial residues after thermochemical and enzymatic pretreatment. Front. Sustain. Food Syst. 2019, 3, 92. [CrossRef]

87. Montané, D.; Salvadó, J.; Torras, C.; Farriol, X. High-temperature dilute-acid hydrolysis of olive stones for furfural production. Biomass Bioenergy 2002, 22, 295-304. [CrossRef]

88. Nabarlatz, D.; Ebringerová, A.; Montané, D. Autohydrolysis of agricultural by-products for the production of xylo-oligosaccharides. Carbohydr. Polym. 2007, 69, 20-28. [CrossRef]

89. Hernández, V.; Romero-García, J.M.; Dávila, J.A.; Castro, E.; Cardona, C.A. Techno-economic and environmental assessment of an olive stone based biorefinery. Resour. Conserv. Recycl. 2014, 92, 145-150. [CrossRef]

90. Goldfarb, J.L.; Buessing, L.; Gunn, E.; Lever, M.; Billias, A.; Casoliba, E.; Schievano, A.; Adani, F. Novel integrated biorefinery for olive mill waste management: Utilization of secondary waste for water treatment. ACS Sustain. Chem. Eng. 2017, 5, 876-884. [CrossRef]

91. Acharya, B.; Sule, I.; Dutta, A. A review on advances of torrefaction technologies for biomass processing. Biomass Convers. Biorefinery 2012, 2, 349-369. [CrossRef]

92. Costa, F.F.; Wang, G.; Costa, M. Combustion kinetics and particle fragmentation of raw and torrified pine shells and olive stones in a drop tube furnace. Proc. Combust. Inst. 2015, 35, 3591-3599. [CrossRef]

93. Cuevas, M.; Martínez Cartas, M.L.; Sánchez, S. Effect of short-time hydrothermal carbonization on the properties of hydrochars prepared from olive-fruit endocarps. Energy Fuels 2019, 33, 313-322. [CrossRef]

94. Álvarez-Murillo, A.; Román, S.; Ledesma, B.; Sabio, E. Study of variables in energy densification of olive stone by hydrothermal carbonization. J. Anal. Appl. Pyrolysis 2015, 113, 307-314. [CrossRef]

95. Sánchez, F.; San Miguel, G. Improved fuel properties of whole table olive stones via pyrolytic processing. Biomass Bioenergy 2016, 92, 1-11. [CrossRef]

96. Martín-Lara, M.A.; Ronda, A.; Blázquez, G.; Pérez, A.; Calero, M. Pyrolysis kinetics of the lead-impregnated olive stone by non-isothermal thermogravimetry. Process Saf. Environ. Prot. 2018, 113, 448-458. [CrossRef]

97. Bartocci, P.; D’Amico, M.; Moriconi, N.; Bidini, G.; Fantozzi, F. Pyrolysis of olive stone for energy purposes. Energy Procedia 2015, 82, 374-380. [CrossRef]

98. Marcilla, A.; García, A.N.; Pastor, M.V.; León, M.; Sánchez, A.J.; Gómez, D.M. Thermal decomposition of the different particles size fractions of almond shells and olive stones. Thermal behaviour changes due to the milling processes. Thermochim. Acta 2013, 564, 24-33. [CrossRef]

99. Gomez-Martin, A.; Chacartegui, R.; Ramirez-Rico, J.; Martinez-Fernandez, J. Performance improvement in olive stone's combustion from a previous carbonization transformation. Fuel 2018, 228, 254-262. [CrossRef]

100. Adánez, J.; De Diego, L.F.; García-Labiano, F.; Abad, A.; Abanades, J.C. Determination of biomass char combustion reactivities for FBC applications by a combined method. Ind. Eng. Chem. Res. 2001, 40, 4317-4323. [CrossRef]

101. Karakaş, C.; Özçimen, D.; İnan, B. Potential use of olive stone biochar as a hydroponic growing medium. J. Anal. Appl. Pyrolysis 2017, 125, 17-23. [CrossRef] 
102. Molina-Sabio, M.; Jesús Sánchez-Montero, M.; Juarez-Galan, J.M.; Salvador, F.; Rodríguez-Reinoso, F.; Salvador, A. Development of porosity in a char during reaction with steam or supercritical water. J. Phys. Chem. B 2006, 110, 12360-12364. [CrossRef]

103. Alslaibi, T.M.; Abustan, I.; Ahmad, M.A.; Foul, A.A. Cadmium removal from aqueous solution using microwaved olive stone activated carbon. J. Environ. Chem. Eng. 2013, 1, 589-599. [CrossRef]

104. Hazzaa, R.; Hussein, M. Adsorption of cationic dye from aqueous solution onto activated carbon prepared from olive stones. Environ. Technol. Innov. 2015, 4, 36-51. [CrossRef]

105. Moreno, N.; Caballero, Á.; Morales, J.; Rodríguez-Castellón, E. Improved performance of electrodes based on carbonized olive stones/S composites by impregnating with mesoporous $\mathrm{TiO}_{2}$ for advanced $\mathrm{Li}-\mathrm{S}$ batteries. J. Power Sources 2016, 313, 21-29. [CrossRef]

106. Moreno, N.; Caballero, A.; Hernán, L.; Morales, J. Lithium-sulfur batteries with activated carbons derived from olive stones. Carbon N. Y. 2014, 70, 241-248. [CrossRef]

107. Gómez-Barea, A.; Arjona, R.; Ollero, P. Pilot-plant gasification of olive stone: A technical assessment. Energy Fuels 2005, 19, 598-605. [CrossRef]

108. Di Blasi, C.D.; Signorelli, G.; Portoricco, G. Countercurrent fixed-bed gasification of biomass at laboratory scale. Ind. Eng. Chem. Res. 1999, 38, 2581. [CrossRef]

109. Skoulou, V.; Swiderski, A.; Yang, W.; Zabaniotou, A. Process characteristics and products of olive kernel high temperature steam gasification (HTSG). Bioresour. Technol. 2009, 100, 2444-2451. [CrossRef]

110. Dogru, M. Experimental results of olive pits gasification in a fixed bed downdraft gasifier system. Int. J. Green Energy 2013, 10, 348-361. [CrossRef]

111. Margaritis, N.K.; Grammelis, P.; Vera, D.; Jurado, F. Assessment of operational results of a downdraft biomass gasifier coupled with a gas engine. Procedia-Soc. Behav. Sci. 2012, 48, 857-867. [CrossRef]

112. Rosúa, J.M.; Pasadas, M. Biomass potential in Andalusia, from grapevines, olives, fruit trees and poplar, for providing heating in homes. Renew. Sustain. Energy Rev. 2012, 16, 4190-4195. [CrossRef]

113. Morán, J.C.; Míguez, J.L.; Porteiro, J.; Patiño, D.; Granada, E. Low-quality fuels for small-scale combustion boilers: An experimental study. Energy Fuels 2015, 29, 3064-3081. [CrossRef]

114. González, J.F.; González-García, C.M.; Ramiro, A.; González, J.; Sabio, E.; Gañán, J.; Rodríguez, M.A. Combustion optimisation of biomass residue pellets for domestic heating with a mural boiler. Biomass Bioenergy 2004, 27, 145-154. [CrossRef]

115. Mami, M.A.; Mätzing, H.; Gehrmann, H.J.; Stapf, D.; Bolduan, R.; Lajili, M. Investigation of the olive mill solid wastes pellets combustion in a counter-current fixed bed reactor. Energies 2018, 11, 1965. [CrossRef]

116. Grammelis, P.; Kakaras, E. Biomass combustion modeling in fluidized beds. Energy Fuels 2005, 19, $292-297$. [CrossRef]

117. Scala, F.; Chirone, R. Characterization and early detection of bed agglomeration during the fluidized bed combustion of olive husk. Energy Fuels 2006, 20, 120-132. [CrossRef]

118. Abreu, P.; Casaca, C.; Costa, M. Ash deposition during the co-firing of bituminous coal with pine sawdust and olive stones in a laboratory furnace. Fuel 2010, 89, 4040-4048. [CrossRef]

119. De Moraes Pinheiro, S.M.; Font, A.; Soriano, L.; Tashima, M.M.; Monzó, J.; Borrachero, M.V.; Payá, J. Olive-stone biomass ash (OBA): An alternative alkaline source for the blast furnace slag activation. Constr. Build. Mater. 2018, 178, 327-338. [CrossRef]

120. Font, A.; Soriano, L.; de Moraes Pinheiro, S.M.; Tashima, M.M.; Monzó, J.; Borrachero, M.V.; Payá, J. Design and properties of $100 \%$ waste-based ternary alkali-activated mortars: Blast furnace slag, olive-stone biomass ash and rice husk ash. J. Clean. Prod. 2020, 243, 118568. [CrossRef]

121. Topal, H.; Taner, T.; Naqvi, S.A.H.; Altınsoy, Y.; Amirabedin, E.; Ozkaymak, M. Exergy analysis of a circulating fluidized bed power plant co-firing with olive pits: A case study of power plant in Turkey. Energy 2017, 140, 40-46. [CrossRef]

122. Vamvuka, D.; Papas, M.; Galetakis, M.; Sfakiotakis, S. Thermal valorization of an animal sludge for energy recovery via co-combustion with olive kernel in a fluidized bed unit: Optimization of emissions. Energy Fuels 2016, 30, 5825-5834. [CrossRef]

123. Manzanares, P.; Ballesteros, I.; Negro, M.J.; González, A.; Oliva, J.M.; Ballesteros, M. Processing of extracted olive oil pomace residue by hydrothermal or dilute acid pretreatment and enzymatic hydrolysis in a biorefinery context. Renew. Energy 2020, 145, 1235-1245. [CrossRef] 
124. García-Martín, J.F.; Barrios, C.C.; Alés-Álvarez, F.J.; Dominguez-Sáez, A.; Alvarez-Mateos, P. Biodiesel production from waste cooking oil in an oscillatory flow reactor. Performance as a fuel on a TDI diesel engine. Renew. Energy 2018, 125, 546-556. [CrossRef]

125. Liang, M.H.; Jiang, J.G. Advancing oleaginous microorganisms to produce lipid via metabolic engineering technology. Prog. Lipid Res. 2013, 52, 395-408. [CrossRef] [PubMed]

126. Lama-Muñoz, A.; Álvarez-Mateos, P.; Rodríguez-Gutiérrez, G.; Durán-Barrantes, M.M.; Fernández-Bolaños, J. Biodiesel production from olive-pomace oil of steam-treated alperujo. Biomass Bioenergy 2014, 67, 443-450. [CrossRef]

127. Dodos, G.S.; Tsesmeli, C.E.; Zannikos, F. Evaluation of the antimicrobial activity of synthetic and natural phenolic type antioxidants in biodiesel fuel. Fuel 2017, 201, 150-161. [CrossRef]

128. Hernández, D.; Astudillo, L.; Gutiérrez, M.; Tenreiro, C.; Retamal, C.; Rojas, C. Biodiesel production from an industrial residue: Alperujo. Ind. Crops Prod. 2014, 52, 495-498. [CrossRef]

129. Akgün, N.; Išcan, E. Effects of process variables for biodiesel production by transesterification. Eur. J. Lipid Sci. Technol. 2007, 5, 486-492. [CrossRef]

130. Yücel, Y. Optimization of biocatalytic biodiesel production from pomace oil using response surface methodology. Fuel Process. Technol. 2012, 99, 97-102. [CrossRef]

131. Ouachab, N.; Tsoutsos, T. Study of the acid pretreatment and biodiesel production from olive pomace oil. J. Chem. Technol. Biotechnol. 2013, 88, 1175-1181. [CrossRef]

132. Willson, R.M.; Wiesman, Z.; Brenner, A. Analyzing alternative bio-waste feedstocks for potential biodiesel production using time domain (TD)-NMR. Waste Manag. 2010, 30, 1881-1888. [CrossRef]

133. Alvarez Serafni, M.S.; Tonetto, G.M. Production of fatty acid methyl esters from an olive oil industry waste. Brazilian J. Chem. Eng. 2019, 36, 285-297. [CrossRef]

134. Ayadi, I.; Belghith, H.; Gargouri, A.; Guerfali, M. Screening of new oleaginous yeasts for single cell oil production, hydrolytic potential exploitation and agro-industrial by-products valorization. Process Saf. Environ. Prot. 2018, 119, 104-114. [CrossRef]

135. Kamoun, O.; Ayadi, I.; Guerfali, M.; Belghith, H.; Gargouri, A.; Trigui-Lahiani, H. Fusarium verticillioides as a single-cell oil source for biodiesel production and dietary supplements. Process Saf. Environ. Prot. 2018, 118, 68-78. [CrossRef]

136. Kamoun, O.; Muralitharan, G.; Belghith, H.; Gargouri, A.; Trigui-Lahiani, H. Suitable carbon sources selection and ranking for biodiesel production by oleaginous Mucor circinelloides using multi-criteria analysis approach. Fuel 2019, 257, 116117. [CrossRef]

137. Tekin, A.R.; Dalgiç, A.C. Biogas production from olive pomace. Resour. Conserv. Recycl. 2000, 30, $301-313$. [CrossRef]

138. Milanese, M.; De Risi, A.; De Riccardis, A.; Laforgia, D. Numerical study of anaerobic digestion system for olive pomace and mill wastewater. Energy Procedia 2014, 45, 141-149. [CrossRef]

139. Orive, M.; Cebrián, M.; Zufía, J. Techno-economic anaerobic co-digestion feasibility study for two-phase olive oil mill pomace and pig slurry. Renew. Energy 2016, 97, 532-540. [CrossRef]

140. Riggio, V.; Comino, E.; Rosso, M. Energy production from anaerobic co-digestion processing of cow slurry, olive pomace and apple pulp. Renew. Energy 2015, 83, 1043-1049. [CrossRef]

141. El Gnaoui, Y.; Sounni, F.; Bakraoui, M.; Karouach, F.; Benlemlih, M.; Barz, M.; El Bari, H. Anaerobic co-digestion assessment of olive mill wastewater and food waste: Effect of mixture ratio on methane production and process stability. J. Environ. Chem. Eng. 2020, 8, 103874. [CrossRef]

142. De la Lama, D.; Borja, R.; Rincón, B. Performance evaluation and substrate removal kinetics in the semi-continuous anaerobic digestion of thermally pretreated two-phase olive pomace or "Alperujo". Process Saf. Environ. Prot. 2017, 105, 288-296. [CrossRef]

143. Elalami, D.; Carrere, H.; Abdelouahdi, K.; Garcia-Bernet, D.; Peydecastaing, J.; Vaca-Medina, G.; Oukarroum, A.; Zeroual, Y.; Barakat, A. Mild microwaves, ultrasonic and alkaline pretreatments for improving methane production: Impact on biochemical and structural properties of olive pomace. Bioresour. Technol. 2020, 299, 22591. [CrossRef]

144. Barbanera, M.; Lascaro, E.; Stanzione, V.; Esposito, A.; Altieri, R.; Bufacchi, M. Characterization of pellets from mixing olive pomace and olive tree pruning. Renew. Energy 2016, 88, 185-191. [CrossRef] 
145. Hernández, D.; Fernández-Puratich,H.; Rebolledo-Leiva, R.; Tenreiro, C.; Gabriel, D. Evaluation of sustainable manufacturing of pellets combining wastes from olive oil and forestry industries. Ind. Crops Prod. 2019, 134, 338-346. [CrossRef]

146. Lajili, M.; Guizani, C.; Escudero Sanz, F.J.; Jeguirim, M. Fast pyrolysis and steam gasification of pellets prepared from olive oil mill residues. Energy 2018, 150, 61-68. [CrossRef]

147. Benavente, V.; Calabuig, E.; Fullana, A. Upgrading of moist agro-industrial wastes by hydrothermal carbonization. J. Anal. Appl. Pyrolysis 2015, 113, 89-98. [CrossRef]

148. Zribi, M.; Lajili, M.; Escudero-Sanz, F.J. Hydrogen enriched syngas production via gasification of biofuels pellets/powders blended from olive mill solid wastes and pine sawdust under different water steam/nitrogen atmospheres. Int. J. Hydrog. Energy 2019, 44, 11280-11288. [CrossRef]

149. Schacht, C.; Zetzl, C.; Brunner, G. From plant materials to ethanol by means of supercritical fluid technology. J. Supercrit. Fluids 2008, 46, 299-321. [CrossRef]

150. Lee, Z.; Park, S. Particulate and gaseous emissions from a direct-injection spark ignition engine fueled with bioethanol and gasoline blends at ultra-high injection pressure. Renew. Energy 2020, 149, 80-90. [CrossRef]

151. Redel-Macías, M.D.; Pinzi, S.; Leiva, D.; Cubero-Atienza, A.J.; Dorado, M.P. Air and noise pollution of a diesel engine fueled with olive pomace oil methyl ester and petrodiesel blends. Fuel 2012, 95, 615-625. [CrossRef]

152. López, I.; Pinzi, S.; Leiva-Candia, D.; Dorado, M.P. Multiple response optimization to reduce exhaust emissions and fuel consumption of a diesel engine fueled with olive pomace oil methyl ester/diesel fuel blends. Energy 2016, 117, 398-404. [CrossRef]

153. Özçelik, A.E.; Acaroğlu, M.; Köse, H. Determination of combustion characteristics of olive pomace biodiesel-Eurodiesel fuel mixtures. Energy Sources Part A Recover. Util. Environ. Eff. 2019, 42, 1476-1489. [CrossRef]

(C) 2020 by the authors. Licensee MDPI, Basel, Switzerland. This article is an open access article distributed under the terms and conditions of the Creative Commons Attribution (CC BY) license (http://creativecommons.org/licenses/by/4.0/). 